\title{
$\pi$-Linkage effect of push-pull-structure organic small molecules for photovoltaic application
}

\author{
Rui Wu, Lunxiang Yin and Yanqin $\mathrm{Li}^{*}$
}

\begin{abstract}
Much attention has been paid to the push-pullstructure organic small molecule (OSM) materials for photovoltaic (PV) application in the past decade, due to their facile reduction of energy band gap $\left(E_{\mathrm{g}}\right)$ and effective control of PV properties. $\pi$-bridge plays an important role in the push-pull-structure OSMs since an appropriate $\pi$-linkage is crucial for improving the PV performance of organic solar cells (OSCs). In this review, various $\pi$-bridge groups (thiophene, alkene, alkyne, arene and heterocycle) and the pertinent $\pi$-linkage effect will be systematically summarized. These results suggest that the in-depth study of the $\pi$-linkage effect is essential to deeply understanding the relationship between the molecular structure and property, thus improving PV performance.
\end{abstract}

Keywords: $\pi$-linkage effect, push-pull-structure, photovoltaic, organic solar cells

\section{INTRODUCTION}

Due to the exhaustion of fossil energy resources and anthropogenic climate change, it is necessary to find clean and renewable alternative energy sources [1-3]. Solar energy has the potential to be the long-term and promising succedaneums for fossil energy due to its non-polluting, renewable and inexhaustible properties. In this respect, organic solar cells (OSCs) are regarded as a distinguished alternative than the conventional silicon-based solar cells, especially the solution-processed organic small molecule solar cells (OSM-SCs) owing to their well-defined chemical structure, better batch-to-batch reproducibility, easy purification and more straightforward analysis of structureproperty relationships [4-7].

According to the materials, OSCs can be divided into two main classes: polymer organic solar cells (PSCs) and small molecule organic solar cells (SM-OSCs) [8]. In this review, we focus on OSCs based on small molecules. In addition to incident light power density $\left(P_{\text {in }}\right)$, there are several main parameters to describe the performance of OSCs, as shown in Fig. 1: (1) short-circuit current density (JSC) and open-circuit voltage $\left(V_{O C}\right)$, both parameters are generally measured at a standard irradiation $\left(100 \mathrm{~mW} \mathrm{~cm}^{-2}\right) ;$ (2) fill factor $(F F)$ is a parameter to denote the losses resulted from the resistance of the OSCs; (3) power conversion efficiency (PCE) is the main parameter to evaluate the photovoltaic (PV) performance $[9,10]$.

Tremendous efforts have been devoted by researchers to improving the efficiency of OSCs such as device optimization and morphology control [11-14], especially the design of active layer material [15-17]. Recently, a notable PCE of $10.08 \%$ has been achieved by Kan and co-workers [18], which demonstrated that OSM-PV materials have bright future. Actually, active layer materials can be generally classified as donor materials and acceptor materials. So far, most commonly used acceptor materials for OSMSCs are fullerene derivatives, such as [6,6]-phenyl- $\mathrm{C}_{61}$-butyric acid methyl ester $\left(\mathrm{PC}_{61} \mathrm{BM}\right)$ and $[6,6]$-phenyl- $\mathrm{C}_{71}$-butyric acid methyl ester $\left(\mathrm{PC}_{71} \mathrm{BM}\right)$, due to their excellent solubility, low lying energy levels and high electron mobility property. So the most basic issue is to design the optimized OSMs as the donor materials with the efficient light absorption and appropriate energy level. Benefited from easily reduction of the energy band gap $\left(E_{\mathrm{g}}\right)$ and effectively control the PV properties, much attention has been paid to the push-pull-structure OSMs containing $\pi$-bridge in the past decade. The so-called push-pull-structure is a kind of OSMs containing structural units in which electron-deficient (A) group and electron-rich (D) group are connected with conjugated $\pi$-bridge, as shown in Fig. 1 . There have been many reviews focused on the bulk heterojunction (BHJ) OSCs based on OSM donors [19-21]. The contents of those reviews included the design of donor/acceptor groups, backbone conjugation length effect, and the

School of Chemistry, Dalian University of Technology, Dalian 116024, China

* Corresponding author (email: liyanqin@dlut.edu.cn) 


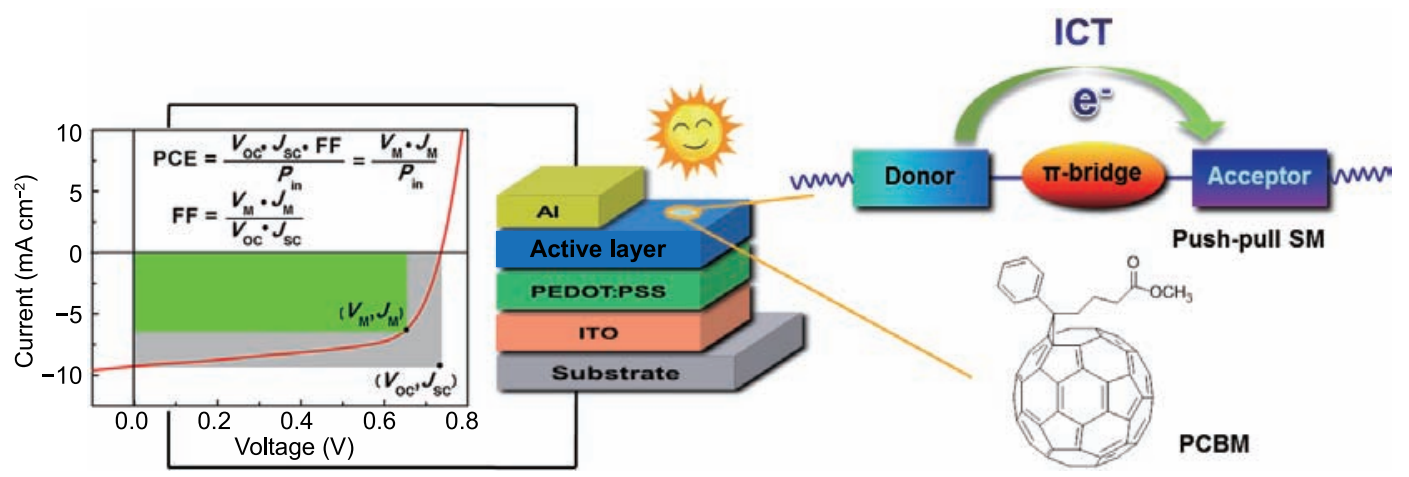

Figure 1 Typical push-pull-structure OSMs with an architecture of BHJ PV-device and $J$ - $V$ curve of the device.

optimization of device performance. Relatively, few attention was paid to $\pi$-linkage effect of various bridges between $\mathrm{D}$ and $\mathrm{A}$ units.

In this review article, we will systematically summarize various $\pi$-bridge and the pertinent linkage effect on push-pull-structure OSMs. Several classes of $\pi$-bridge, thiophene, alkene, alkyne, arene and heterocycle will be discussed in details. The in-depth study of the $\pi$-linkage effect is essential to deeply understanding the relationship between the molecular structure and property, thus improving PV performance.

\section{$\pi$-LINKAGE WITH THIOPHENE AND ITS DERIVATIVES}

Thiophene and its derivatives can be used as an effective conjugated $\pi$-bridge to connect $\mathrm{D}$ and A moieties of a molecule, because it not only possesses a high charge transport property in the $\mathrm{D}$-A backbone, but also enhances the conjugation degree of the molecule. A sufficiently longer conjugation bridge like thiophene [22-24], oligothiophene derivatives $[25,26]$ or fused-thiophene provides an extension of the absorption towards the red and NIR wavelengths as well as an increase of the absorption coefficient due to strong intramolecular charge transfer (ICT). More detailed discussion on $\pi$-bridge of thiophene and its derivatives are depicted in the following part. The chemical structures of compounds employing thiophene and its derivatives as $\pi$-bridge are shown in Figs 2-4, and Table 1 provided a summary of their device parameters.

\section{Thiophene-linkage}

Thiophene as one of the simplest bridges among thiophene derivatives plays an important role in push-pull-structure OSMs, which ensures an efficient ICT and a higher molar absorptivity. Besides, to broaden the absorption region, thiophene-bridge is also used to extend the conju- gated length. The chemical structures of compounds employing thiophene as $\pi$-bridge are shown in Fig. 2 .

Two D-A-D typed molecules $\mathbf{1 a}$ and $\mathbf{1 b}$ were demonstrated by Shang et al. [27] in 2010, both containing triphenylamine as the donor units and benzothiadiazole as the acceptor units. The effect of the link pattern (thiophene and thienylenevinylene) was exactly investigated here. 1a with thiophene-bridge is crystalline, while its thienylenevinylene linked counterpart $\mathbf{1 b}$ is amorphous. Compared with 1a, $\mathbf{1 b}$ showed a red-shifted, broader absorption which was mainly assigned to the extended delocalized $\pi$-conjugation system in structure $\mathbf{1 b}$. Owing to the deep-lying highest occupied molecular orbital (HOMO) energy level of $\mathbf{1 a}(-5.2 \mathrm{eV})$ than $\mathbf{1 b}(-4.9 \mathrm{eV})$, the device based on 1a:PC ${ }_{61} \mathrm{BM}$ blend exhibited a higher PCE $(0.56 \%$ vs. $0.42 \%)$. Finally the device based on $1 \mathrm{a}: \mathrm{PC}_{71} \mathrm{BM}$ $(1: 3 w / w)$ obtained a PCE of $1.23 \%$.

Thienylenevinylene as the conjugated $\pi$-bridge in OSM-SCs was also reported by Zhang et al. [28] in 2011. In order to obtain better solubility, charge-transporting and film-forming properties, styrene was substituted with thienylenevinylene and 4-hexyl-thienylenevinylene respectively as conjugated $\pi$-bridge in $\mathbf{2 a}$ and $\mathbf{2} \mathbf{b}$. Especially the hexyl-substituted thienylenevinylene bridge was considered to further improve the solubility and film-forming properties of the molecule. Both $\mathbf{2 a}$ and $\mathbf{2} \mathbf{b}$ demonstrated a broad absorption from 350 to $650 \mathrm{~nm}$. The $\mathrm{BHJ}$ devices based on $\mathbf{2 a}$ and $\mathbf{2} \mathbf{b}$ as the donor and $\mathrm{PC}_{71} \mathrm{BM}$ as the acceptor $(1: 3 w / w)$, showed PCEs of $2.06 \%$ and $2.10 \%$, respectively, indicating that thienylenevinylene is a kind of promising conjugated $\pi$-bridge.

In 2012, Shi et al. [29] reported a linear D-A-D typed OSM 3 with triphenylamine as the donor group and thiazolothiazole as the acceptor group. In order to obtain an excellent solubility, n-dodecyl-substituted thiophene was employed as the $\pi$-bridge. The best $\mathrm{BHJ}$ device based on 3 : 


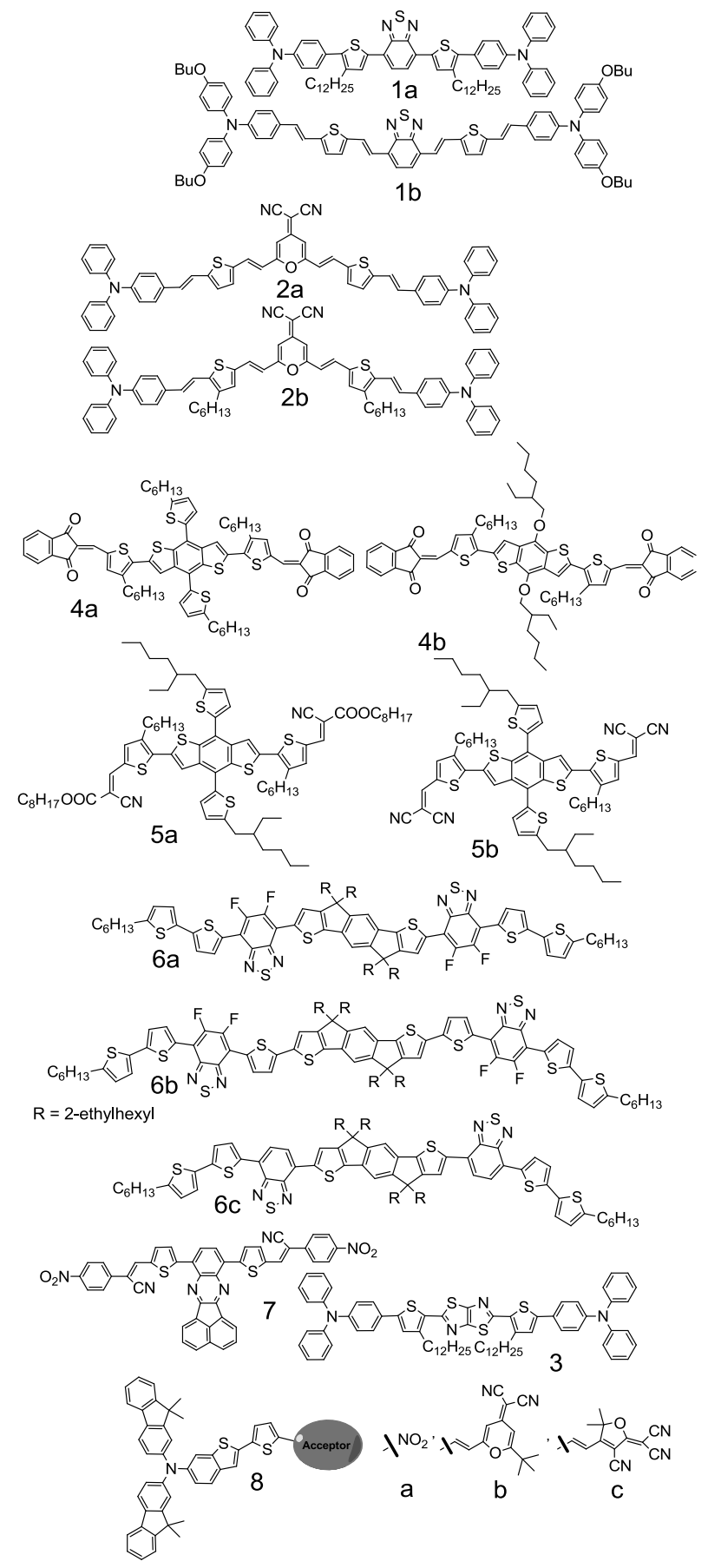

Figure 2 Chemical structures of compounds with thiophene as $\pi$-linkage.

$\mathrm{PC}_{71} \mathrm{BM}(1: 4 w / w)$ afforded a PCE as high as $3.73 \%$ after thermal annealing at $110^{\circ} \mathrm{C}$ for $10 \mathrm{~min}$, which is one of the top PCE for solution-processed BHJ-OSCs based on OSMs at that time.

A-D-A structured OSMs $4 \mathbf{a}$ with bithienyl-substituted
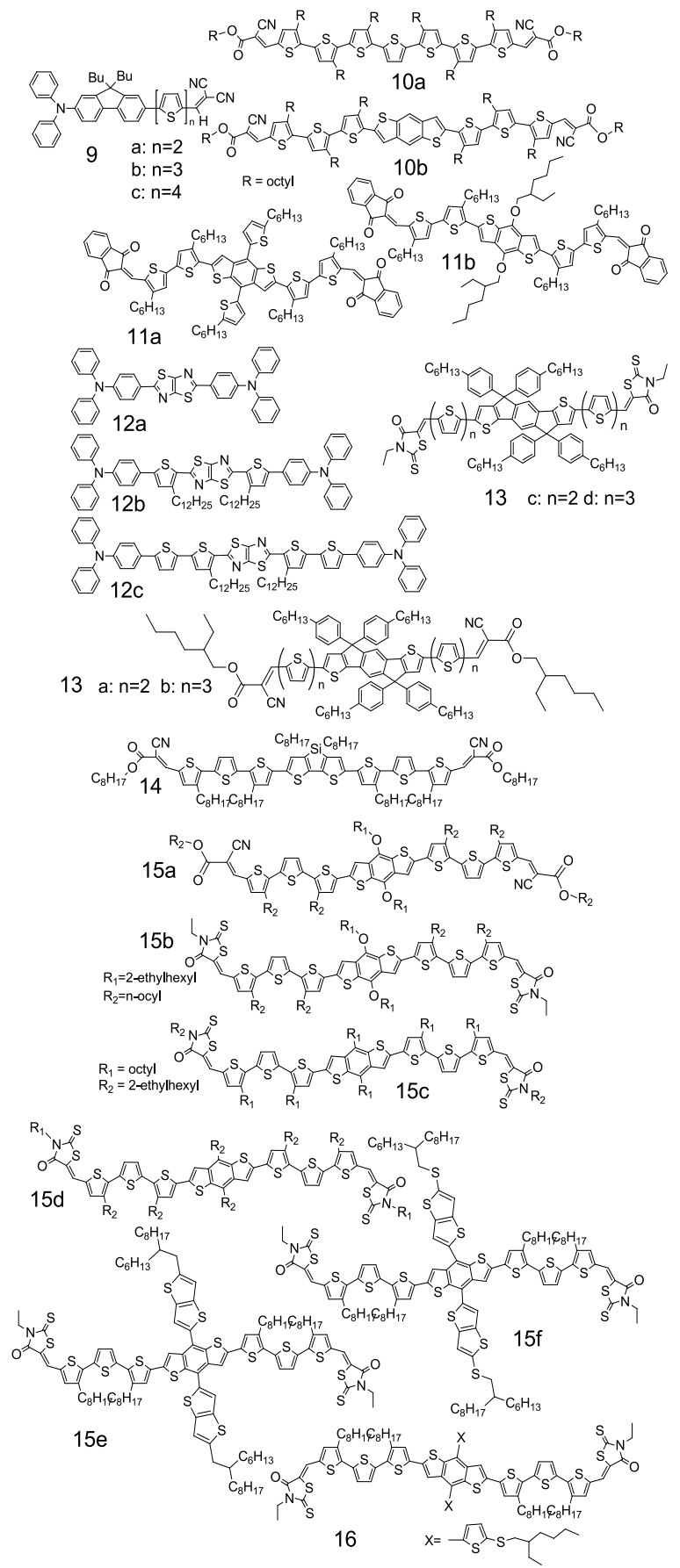

Figure 3 Chemical structures of compounds using oligothiophene as $\pi$-linkage.

benzodithiophene (BDTT) as the central donor building block, indenedione (ID) as the terminal acceptor group, and thiophene as the $\pi$-bridge was demonstrated by Shen et al. [30] in 2013. 4b with alkoxy side chains on BDT were also synthesized for comparison. Benefited from the D-A 


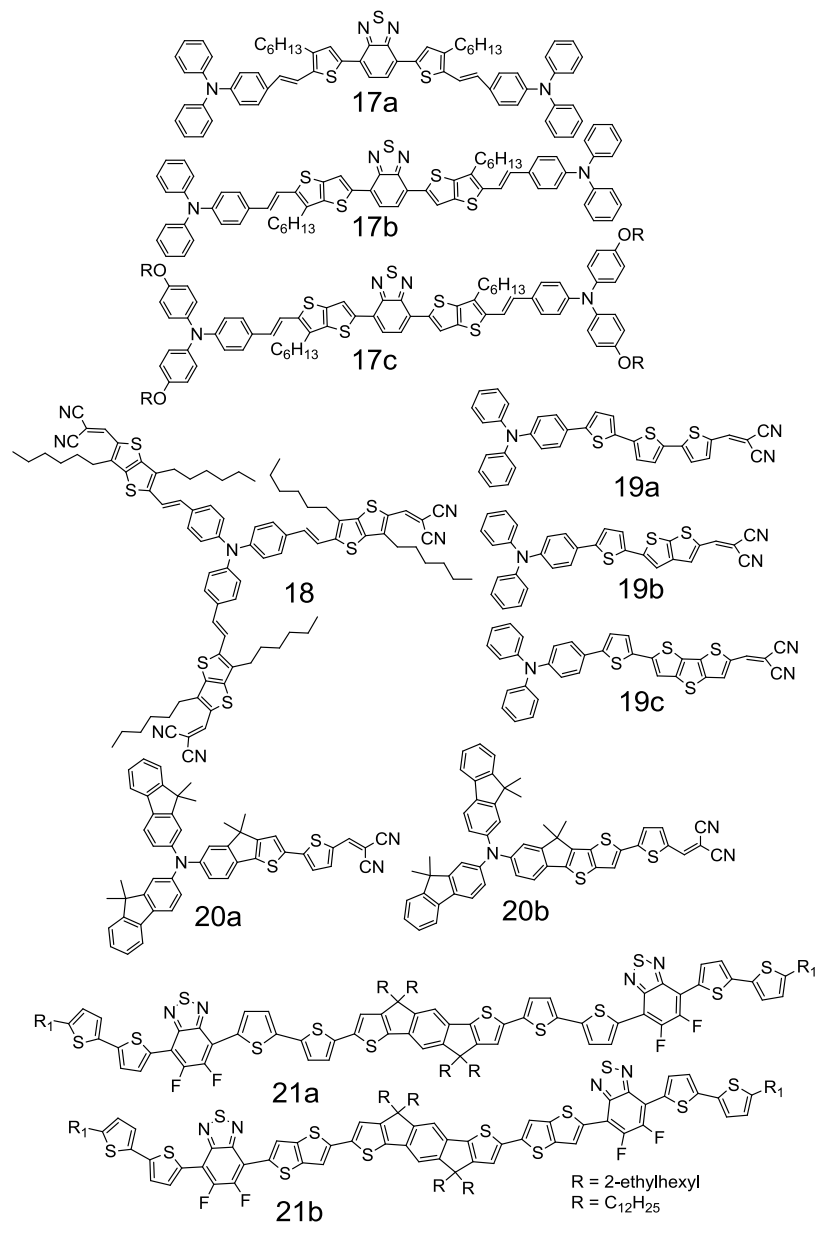

Figure 4 Chemical structures of compounds using fused-thiophene as $\pi$-linkage.

molecular structure with thiophene $\pi$-bridge, the absorption spectra of $\mathbf{4 a}$ and $\mathbf{4 b}$ exhibited a strong and broad absorption band in the range from 450 to $650 \mathrm{~nm}$. The PCE values of the device based on the OSM:PC ${ }_{70} \mathrm{BM}(1.5: 1 w / w)$ are $5.67 \%$ for $\mathbf{4 a}, 4.15 \%$ for $\mathbf{4 b}$. High PV performance of device suggested that thiophene is a kind of effective bridge within D-A typed OSMs.

Two novel short-conjugated A- $\pi$-D- $\pi$-A small molecules 5a and $\mathbf{5 b}$ were reported by Yin et al. [31]. Both employed mono-thiophene unit as the $\pi$-conjugation bridge, benzodithiophene (BDT) derivative as the donor part, and 2-cyano-3-octyloxy-3-oxo-1-propenyl (COOP) or dicyanovinyl (DCV) as the terminal acceptor unit. The 5a:PC ${ }_{61} \mathrm{BM}$ based device exhibited a PCE of $0.69 \%$, whereas the $5 \mathbf{b}: \mathrm{PC}_{61} \mathrm{BM}$ based device showed PCE of $4.48 \%$, which indicated that the BDT derivative with only one thiophene as the $\pi$-bridge is a kind of potential donor material for high efficiency organic solar cell.
The effects of thiophene $\pi$-bridge and multiple-fluorinated modules on the photovoltaic properties were investigated by Cao's group [32]. Very recently, they showed three molecule $\mathbf{6 a}-\mathbf{c}$, by incorporating multiple fluorine substituents of benzothiadiazole and inserting thiophene spacers, the PV performance is dramatically improved. Compared with 6a, inserting thiophene moieties not only enhance the absorption intensity but also increase the vibrational feature significantly. Through the solvent vapor annealing (SVA) treatment, a high PCE of $8.1 \%$ with an outstanding $F F$ of 0.76 was achieved by using $6 \mathbf{b} / \mathrm{PC}_{71} \mathrm{BM}$. The results demonstrated that the PCE of small molecules can be significantly increased through careful molecular structure engineering and blend films morphology optimization.

In addition, there are more OSMs employing thiophene-linkage which exhibit an excellent PV performance. For instance, In 2010, Mikroyannidis and co-workers [33] reported a low-band-gap OSM 7 with thiophene as the bridge. The BHJ devices received PCEs of $2.21 \%$ and $3.23 \%$ on the basis of the as-cast and thermally annealed blend respectively. In 2012, three efficient push-pull-structure OSMs 8a-c were reported by Kim and co-workers [34]. Donor unit and various acceptor units were linked by thiophene or vinyl thiophene bridge. Those OSMs exhibited favorable PV performance. Especially $\mathbf{8 b}$ exhibited the best PCE of $3.22 \%$ with $J_{\mathrm{SC}}$ of $9.64 \mathrm{~mA} \mathrm{~cm}^{-2}, V_{\mathrm{OC}}$ of $0.80 \mathrm{~V}$ and $F F$ of 0.42 in $\mathrm{BHJ}$ devices with $\mathrm{TiO}_{x}$ thin layer.

\section{Oligothiophene-linkage}

Among thiophene and its derivatives, oligothiophene architecture is very effective to tailor molecular D and A moieties, producing molecules where the HOMO level and the lowest unoccupied orbital (LUMO) level can be controlled for the design of molecule with a low $E_{\mathrm{g}}$ [36-39]. Besides, molecules using oligothiophene as a highly extended $\pi$-conjugated bridge not only broaden the absorption region but also promote strong $\pi-\pi$ stacking of conjugated backbones [40-45]. The chemical structures of compounds using oligothiophene as $\pi$-linkage are shown in Fig. 3.

In 2008, Xia et al. [37] reported a series of diphenylaminofluorenyl and dicyanovinyl di-substituted oligothiophenes $9 \mathbf{a}-\mathbf{c}$, which exhibited a stronger absorption peak with $\lambda_{\max }=514-526 \mathrm{~nm}$ and a narrow optical $E_{\mathrm{g}}$ with $E_{\mathrm{g}}{ }^{\mathrm{opt}}$ $=1.92-1.82 \mathrm{eV}$, showing the longer oligothiophene length the better $\pi-\pi$ stacking of the molecules. $9 \mathrm{c}$ based device showed the best PV performance with a PCE of $2.67 \%$ after thermal annealing at $100^{\circ} \mathrm{C}$ for $20 \mathrm{~min}$. 
Table 1 Device parameters of compounds using thiophene and its derivatives as $\pi$-linkage

\begin{tabular}{|c|c|c|c|c|c|c|c|}
\hline Compound & $\pi$-bridge & $J_{\mathrm{SC}}\left(\mathrm{mA} \mathrm{cm}^{-2}\right)$ & $V_{\mathrm{OC}}(\mathrm{V})$ & $\mathrm{FF}$ & PCE (\%) & Device optimization & Ref. \\
\hline 1a & Thiophene & 3.50 & 0.86 & 0.41 & 1.23 & $\mathrm{D} / \mathrm{A}$ radio & \multirow{2}{*}[27]{} \\
\hline $1 b$ & Thienylenevinylene & 1.89 & 0.62 & 0.36 & 0.42 & 1 & \\
\hline $2 a$ & Thienylenevinylene & 5.94 & 0.79 & 0.44 & 2.06 & / & \multirow{2}{*}[28]{} \\
\hline $2 b$ & 4-hexyl-thienylenevinylene & 6.78 & 0.78 & 0.39 & 2.10 & l & \\
\hline 3 & Thiophene & 9.39 & 0.91 & 0.437 & 3.73 & $\mathrm{TA}^{\mathrm{a})} 110^{\circ} \mathrm{C} \mathrm{D} / \mathrm{A}$ radio & {$[29]$} \\
\hline $4 a$ & Thiophene & 10.07 & 1.03 & 0.547 & 5.67 & / & \multirow{2}{*}{30} \\
\hline $4 b$ & Thiophene & 9.47 & 0.91 & 0.482 & 4.15 & I & \\
\hline $5 \mathbf{a}$ & Thiophene & 2.28 & 1.04 & 0.29 & 0.69 & I & \multirow{2}{*}[31]{} \\
\hline $5 \mathbf{b}$ & Thiophene & 8.54 & 0.93 & 0.56 & 4.48 & I & \\
\hline $6 a$ & 1 & 9.0 & 0.99 & 0.38 & 3.4 & / & \multirow{3}{*}[32]{} \\
\hline $6 b$ & Thiophene & 11.9 & 0.9 & 0.76 & 8.1 & $\mathrm{SVA}^{\mathrm{b}}$ & \\
\hline $6 c$ & I & 7.2 & 0.90 & 0.38 & 2.5 & I & \\
\hline 7 & Thiophene & 7.13 & 0.84 & 0.54 & 3.23 & TA $100^{\circ} \mathrm{C}$ & {$[33]$} \\
\hline $8 \mathbf{a}$ & Thiophene & 8.54 & 0.75 & 0.33 & 2.14 & I & \multirow{3}{*}[34]{} \\
\hline $\mathbf{8 b}$ & Thienylenevinylene & 8.22 & 0.79 & 0.34 & 2.22 & TA $100^{\circ} \mathrm{C}$ & \\
\hline $8 c$ & Thienylenevinylene & 9.64 & 0.80 & 0.42 & 3.22 & $\mathrm{TA} 100^{\circ} \mathrm{C} \mathrm{TiO}_{x}$ Layer & \\
\hline $9 a$ & Oligothiophene & 4.92 & 0.89 & 0.36 & 1.56 & $\mathrm{TA} 100^{\circ} \mathrm{C}$ & \multirow{3}{*}[37]{} \\
\hline $9 b$ & Oligothiophene & 6.25 & 0.89 & 0.38 & 2.12 & TA $100^{\circ} \mathrm{C}$ & \\
\hline $9 c$ & Oligothiophene & 6.05 & 0.91 & 0.48 & 2.67 & TA $100^{\circ} \mathrm{C}$ & \\
\hline $10 a$ & Oligothiophene & 10.74 & 0.86 & 0.55 & 5.08 & I & \multirow{2}{*}[25]{} \\
\hline $10 b$ & Oligothiophene & 9.77 & 0.93 & 0.599 & 5.44 & $\mathrm{D} / \mathrm{A}$ radio & \\
\hline $11 \mathrm{a}$ & Bithiophene & 11.05 & 0.92 & 0.664 & 6.75 & $\mathrm{D} / \mathrm{A}$ radio & \multirow{2}{*}[30]{} \\
\hline $11 b$ & Bithiophene & 8.58 & 0.92 & 0.648 & 5.11 & 1 & \\
\hline $12 a$ & I & 6.08 & 0.86 & 0.415 & 2.19 & $\mathrm{D} / \mathrm{A}$ radio & \multirow{3}{*}[46]{} \\
\hline $12 b$ & Thiophene & 9.38 & 0.90 & 0.428 & 3.73 & $\mathrm{TA} 110^{\circ} \mathrm{C} \mathrm{D} / \mathrm{A}$ radio & \\
\hline $12 \mathrm{c}$ & Bithiophene & 9.74 & 0.85 & 0.47 & 4.05 & $\mathrm{TA} 120^{\circ} \mathrm{C} \mathrm{D} / \mathrm{A}$ radio & \\
\hline $13 a$ & Bithiophene & 7.98 & 0.88 & 0.331 & 2.53 & TA $120^{\circ} \mathrm{C}$ & \multirow{4}{*}[35]{} \\
\hline $13 b$ & Terthiophene & 10.52 & 0.91 & 0.496 & 5.00 & $\mathrm{TA} 120^{\circ} \mathrm{C}$ & \\
\hline $13 c$ & Bithiophene & 10.11 & 0.93 & 0.445 & 4.38 & $\mathrm{TA} 120^{\circ} \mathrm{C}$ & \\
\hline $13 d$ & Terthiophene & 11.55 & 0.90 & 0.49 & 5.32 & $\mathrm{TA} 120^{\circ} \mathrm{C}$ & \\
\hline 14 & Dioctyltertthiophene & 11.51 & 0.80 & 0.64 & 5.84 & $\mathrm{D} / \mathrm{A}$ radio & {$[47]$} \\
\hline $15 \mathbf{a}$ & Terthiophene & 8.00 & 0.95 & 0.60 & 4.56 & l & \multirow{2}{*}{48} \\
\hline $15 b$ & Terthiophene & 12.21 & 0.93 & 0.65 & 7.38 & $\mathrm{PDMS}^{\mathrm{c})}$ & \\
\hline $15 c$ & Terthiophene & 12.56 & 0.94 & 0.70 & 8.26 & $\mathrm{TA}^{\mathrm{b})}$ and $\mathrm{SVA}^{\mathrm{c})}$ & [49] \\
\hline $15 d$ & Terthiophene & 13.21 & 0.92 & 0.72 & 8.70 & SVA & \multirow{2}{*}[50]{} \\
\hline $15 e$ & Terthiophene & 12.40 & 0.91 & 0.71 & 8.01 & SVA & \\
\hline $15 f$ & Terthiophene & 14.45 & 0.91 & 0.73 & 9.60 & TA and SVA & {$[51]$} \\
\hline 16 & Terthiophene & 13.45 & 0.97 & 0.705 & 9.20 & $\mathrm{D} / \mathrm{A}$ radio & {$[52]$} \\
\hline $17 \mathbf{a}$ & Thiophene & 4.84 & 0.79 & 0.375 & 1.44 & I & \multirow{3}{*}[53]{} \\
\hline $17 b$ & Thienothiophene & 5.71 & 0.74 & 0.34 & 1.44 & $\mathrm{D} / \mathrm{A}$ radio & \\
\hline $17 \mathrm{c}$ & Thienothiophene & 3.61 & 0.61 & 0.342 & 0.75 & I & \\
\hline 18 & 3,6-dihexyl-thi-eno[3,2-b]thio-phene & 6.80 & 0.96 & 0.435 & 2.87 & $\mathrm{D} / \mathrm{A}$ radio & {$[54]$} \\
\hline $19 a$ & Bithiophene & 7.28 & 0.74 & 0.32 & 1.72 & $\mathrm{D} / \mathrm{A}$ radio & {$[55]$} \\
\hline $19 b$ & Thienothiophene & 7.58 & 0.80 & 0.35 & 2.09 & $\mathrm{D} / \mathrm{A}$ radio & \multirow[t]{2}{*}[55]{} \\
\hline $19 c$ & Thienyl-dithienothiophene & 7.60 & 0.74 & 0.31 & 1.80 & $\mathrm{D} / \mathrm{A}$ radio & \\
\hline $20 a$ & Indenothiophene & 8.74 & 0.66 & 0.44 & 2.52 & $\mathrm{TA} 100^{\circ} \mathrm{C} \mathrm{TiO}_{x}$ Layer & \multirow[t]{2}{*}[56]{} \\
\hline $20 b$ & Indenothienothiophene & 9.50 & 0.77 & 0.44 & 3.21 & TA $100^{\circ} \mathrm{C} \mathrm{TiO}_{x}$ Layer & \\
\hline $21 \mathrm{a}$ & Bithiophene & 8.83 & 0.88 & 0.73 & 5.71 & SVA & \multirow[t]{2}{*}[57]{} \\
\hline $21 b$ & Thienothiophene & 11.33 & 0.89 & 0.75 & 7.57 & SVA & \\
\hline
\end{tabular}

a) TA: thermal annealing; b) SVA: solvent vapor annealing; c) PDMS: polydimethylsiloxane. 
Liu and co-workers [25] reported three push-pull-structure OSMs based on oligothiophene backbone with high PCEs $(4.46 \%-5.08 \%)$ for solution-processed BHJ-OSCs in 2011. Benefited from highly delocalized $\pi$-electrons along the molecular backbone and effective hole-transporting, 10a produced a PCE as high as $5.08 \%$ without any special treatment. Subsequently, they designed and synthesized $10 \mathrm{~b}$ by replacing the central thiophene with a more electron-rich and better planar structure benzo [1,2-b:4,5- $\left.b^{\prime}\right]$ dithiophene (BDT) [26]. This OSM exhibited a high PCE of $5.44 \%$, combined with a $V_{\mathrm{OC}}$ of $0.93 \mathrm{~V}$, a $J_{\mathrm{SC}}$ of $9.77 \mathrm{~mA}$ $\mathrm{cm}^{-2}$ and a notable $F F$ of $59.9 \%$.

Two A-D-A typed OSMs 11a and $\mathbf{1 1 b}$ were reported by Shen et al. [30], both with indenedione as the acceptor groups, bithiophene as the $\pi$-bridge and bithienyl-substituted benzodithiophene or alkoxy-substituted benzodithiophene as the central donor unit. 11a and $\mathbf{1 1 b}$ with bithiophene-bridge possess a higher hole mobility and stronger absorbance than their reference compounds (4a and $\mathbf{4 b}$ ) with thiophene-bridge. The solution-processed OSCs based on the OSMs/PC $\mathrm{PC}_{70} \mathrm{BM}(1.5: 1, w / w)$ yield a PCE of $6.75 \%$ for $11 \mathrm{a}, 5.11 \%$ for $11 \mathbf{b}$, respectively. The results indicate that the OSMs with bithiophene as $\pi$-bridge are promising donor materials for the $\mathrm{BHJ}$-OSCs.

12a-12c are OSMs reported by Cheng and co-workers [46] in 2013, containing thiazolothiazole as the acceptor moieties, triphenylamine as the donor groups and varied number of thiophene as the $\pi$-bridge. With the increasing number of thiophene units, these molecules exhibited bathochromic shift absorption $(300-600 \mathrm{~nm})$ and reduced optical band gaps $(2.55-2.11 \mathrm{eV})$. As a consequence, $\mathrm{BHJ}$ devices based on 12a-12c/ $/ \mathrm{PC}_{71} \mathrm{BM}(1: 4 w / w)$ afforded PCEs of $2.19 \%, 3.73 \%$ and $4.05 \%$, respectively.

In 2014, Bai et al. [35] reported four A-D-A typed OSMs, namely 13a-d, which bearing 4,4,9,9-tetrakis (4-hexylphenyl)-indaceno [1,2-b:5,6-b'] dithiophene as the central donor segments, alkyl cyanoacetate or rhodanine as the terminal acceptor groups and bithiophene or terthiophene as the $\pi$-conjugation bridges. The charge mobility data of $13 / \mathrm{PC}_{71} \mathrm{BM}$ blend films are shown in
Table 2. Obviously, these experimental results illustrate that extending $\pi$-bridges from bithiophene to terthiophene not only facilitate hole mobility but also obviously affect the nanostructure of the blend films. Therefore 13d with rhodanine acceptor and terthiophene bridge exhibited the highest PCE of 5.32\%.

In addition, scores of OSMs taken oligothiophene as the conjugate bridge received favorable PV performance as well. In 2011. Zhou and co-workers [47] reported a linear OSM 14 employing dioctyltertthiophene as the $\pi$-conjugated bridge, and the BHJ cells based on 14 showed a PCE of 5.84\% along with a noticeably high FF of 0.64 . Recently, Chen's research group [48-51] demonstrated a series of small molecules 15a-f containing terthiophene as the $\pi$-bridges, which exhibited excellent PV performance ranging from $8 \%$ to near $10 \%$. In addition, Li's research group [52] also reported a small molecule 16 with terthiophene bridge owning a PCE of 9.2\%. The above PV performances demonstrate that oligothiophene is a kind of effective $\pi$-bridges applied in OSM-PV materials.

\section{Fused-thiophene-linker}

The introduction of fused-thiophene as $\pi$-conjugation bridge could enhance the hole mobility and absorptivity of the compounds, because fused-thiophene usually show a larger $\pi$-conjugation degree and better molecule planarity. Besides, planar fused-thiophene effectively facilitates intermolecular $\pi-\pi$ packing interactions in the solid state, resulting in improved $J_{S C}$ value of the OSCs. Thus, fused-thiophene is also a promising $\pi$-linker in organic $\mathrm{PV}$ materials. The chemical structures of compounds using fused-thiophene as $\pi$-linkage are shown in Fig. 4.

Deng and co-workers [53] reported three low band gap D-A-D typed OSMs 17a-17c in 2011. All of them bearing benzothiadiazole (BT) as the central acceptor units, triphenylamine (TPA) as the end donor units and thiophene (HT) or thienothiophene (HTT) as the $\pi$-linker. Those molecules exhibited broad absorption in the visible range (350-700 nm), lower band gap (1.6-1.7 eV) and good thermal stability. The OSC devices based on $\mathbf{1 7 a}-\mathbf{c}$ reached PCEs of $1.44 \%, 1.44 \%$ and $0.75 \%$, respectively.

Table 2 Hole mobility data of hole-only devices based on 13a, 13b, 13c, and 13d:PC ${ }_{71} B M$ blends (cited from ref [35])

\begin{tabular}{ccccc}
\hline Blend & Donor: $\mathrm{PC}_{71} \mathrm{BM}(w / w)$ & Annealing $\left({ }^{\circ} \mathrm{C}\right)^{\mathrm{a})}$ & $\mu_{\mathrm{h}}\left(\mathrm{cm}^{2} \mathrm{~V}^{-1} \mathrm{~s}^{-1}\right)$ & $\mu_{\mathrm{e}}\left(\mathrm{cm}^{2} \mathrm{~V}^{-1} \mathrm{~s}^{-1}\right)$ \\
\hline 13a: $\mathrm{PC}_{71} \mathrm{BM}$ & $1: 2$ & 120 & $7.5 \times 10^{-5}$ & $8.9 \times 10^{-5}$ \\
13b:PC ${ }_{71} \mathrm{BM}$ & $1: 2$ & 120 & $1.7 \times 10^{-4}$ & $1.3 \times 10^{-5}$ \\
13c: $\mathrm{PC}_{71} \mathrm{BM}$ & $1: 2$ & 120 & $5.0 \times 10^{-5}$ & $2.3 \times 10^{-5}$ \\
13d:PC $\mathrm{P}_{71} \mathrm{BM}$ & $1: 3$ & 120 & $3.0 \times 10^{-4}$ & $2.7 \times 10^{-5}$ \\
\hline
\end{tabular}

a) Annealing for $10 \mathrm{~min}$. 
In 2012, Deng and co-workers [54] subsequently reported a star-shaped D- $\pi$-A typed OSM 18 with TPA as the donor units, dicyanovinyl (DCN) as the acceptor groups and 3,6-dihexyl-thieno [3,2-b] thiophene (DHT) as the $\pi$-bridges. DHT linker imparted high hole mobility and broad absorption for molecule due to the high planarity structure. Two hexyl side chains on the $\pi$-bridge are used to improve solubility and film-forming property of the molecule. As a consequence, the OSC device based on blend of 18: $\mathrm{PC}_{71} \mathrm{BM}(1: 2 w / w)$ exhibited a PCE of $2.87 \%$ with $J_{\mathrm{SC}}$ of $6.80 \mathrm{~mA} \mathrm{~cm}^{-2}, V_{\mathrm{OC}}$ of $0.96 \mathrm{~V}$ and $F F$ of 0.435 .

Three push-pull OSMs 19a-c are demonstrated by Lee et al. [55] in 2013. Electron-rich groups TPA and electrondeficient groups methylene malononitrile are linked by various $\pi$-conjugated thiophene units. Benefited from the effective intermolecular $\pi-\pi$ packing interactions and greater planarity of thienothiophene, $\mathrm{BHJ}$ device made from $\mathbf{1 9 b}$ afford the highest PCE of $2.09 \%$ compared with 19a of $1.72 \%$ and $19 \mathrm{c}$ of $1.80 \%$.

Soon afterwards, Lee et al. [56] reported two OSMs 20a and 20b, comprising planar and rigid indenothiophene (InT) or indenothienothiophene (InTT) as the $\pi$-conjugated thiophene-bridges, bis(9,9-dimethyl-9H-fluoren-2yl)aniline (bisDMFA) as the donor units and methylene malononitrile (MMN) as the acceptor units. Owing to a more effective inter- and intramolecular charge transfers for InTT, the most efficient device based on 20b exhibited a moderate PCE of $3.21 \%$ with $J_{\mathrm{SC}}$ of $9.50 \mathrm{~mA} \mathrm{~cm}{ }^{-2}, V_{\mathrm{OC}}$ of $0.77 \mathrm{~V}$ and $F F$ of 0.44 .

A pair of $\mathrm{D}_{1}$-A-bridge- $\mathrm{D}_{2}$-bridge- $\mathrm{A}-\mathrm{D}_{1}$ type small molecule 21a and $21 \mathbf{b}$ have reported by Cao and co-workers [57]. Different bridges were incorporated into the molecules to investigate the effect of $\pi$-conjugated bridges. The molecule $\mathbf{2 1 b}$ containing two fused thiophene rings as the $\pi$-conjugated bridges exhibited better PV properties compared with analogue system 21a which has dithiophene rings as the conjugated bridges. After SVA treatment with $\mathrm{CH}_{2} \mathrm{Cl}_{2}$, BHJ-OSC device based on $\mathbf{2 1 b}$ showed a high PCE of $7.57 \%$ with $J_{S C}$ of $11.33 \mathrm{~mA} \mathrm{~cm}^{-2}, V_{\text {OC }}$ of 0.89 $\mathrm{V}$ and $F F$ of 0.75 , while device based on 21a owned PCE of $5.71 \%$ with $J_{\mathrm{SC}}$ of $8.83 \mathrm{~mA} \mathrm{~cm}{ }^{-2}, V_{\mathrm{OC}}$ of $0.88 \mathrm{~V}$ and $F F$ of 0.73 . These results illustrate that highly efficient SM-OSCs can be achieved by using fused thiophene bridge and a proper SVA process.

\section{$\pi$-LINKAGE WITH ALKENE AND ITS DERIVATIVES}

Alkene including vinylene, styrene and phenylacrylonitrile is a kind of common $\pi$-bridges [58-68]. Introducing the alkene into D-A typed molecular architecture not only enhance the conjugation degree but also strengthen the coplanarity of the molecule. Benefited from the strict rigidity and coplanarity of the alkene, the molecule backbone will possess a better delocalization and charge stabilization. Besides, alkene also lead to a high hole mobility and facilitating intermolecular interaction. Fig. 5 shows the chemical structures of OSM donors employing alkene as the bridge and Table 3 provides a summary of their device parameters.

In 2009, Zhang and co-workers [69] reported a starshaped OSM 22 containing TPA as the central building blocks, benzothiadiazole-(4-hexyl)thiophene (BT-4HT) as the terminal acceptor units and vinylene as the $\pi$-conjugation bridges. Benefited from the effective connection with conjugated bridge, the absorption spectrum of $\mathbf{2 2}$ demonstrated strong absorption region from 300 to 630 $\mathrm{nm}$. Especially, a peak at $509 \mathrm{~nm}$ could be attributed to the ICT transition between the TPA and BT units. Finally, the best result produced $J_{\mathrm{SC}}$ of $8.58 \mathrm{~mA} \mathrm{~cm}^{-2}, V_{\mathrm{OC}}$ of $0.85 \mathrm{~V}$, FF of $32.7 \%$ and PCE of $2.39 \%$ based on a blend solution of

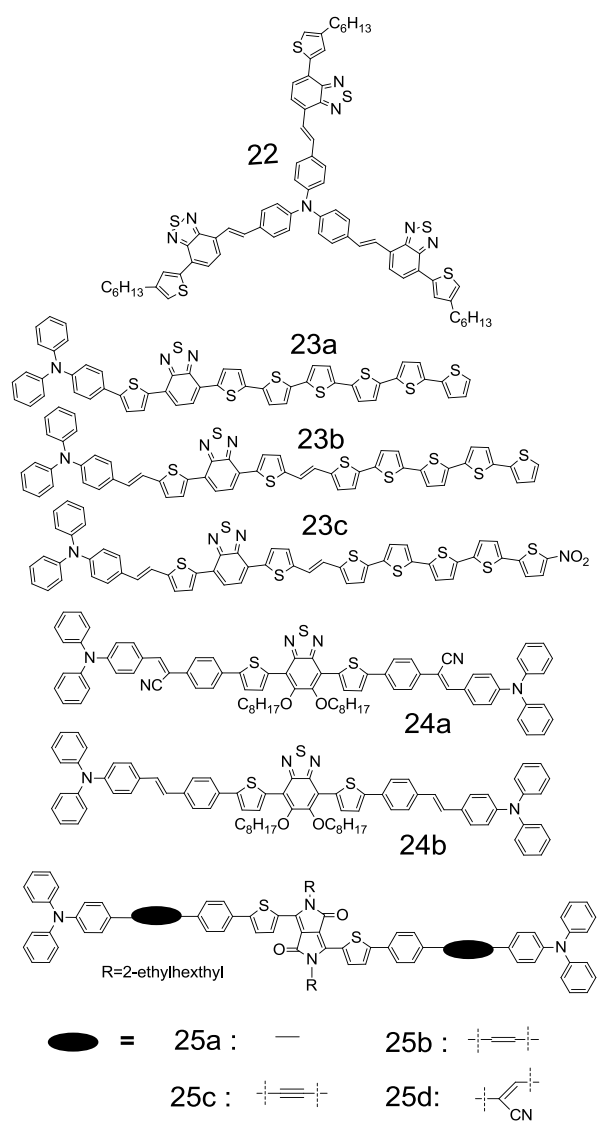

Figure 5 Chemical structures of compounds using alkene as $\pi$-linkage. 
22 and $\mathrm{PC}_{70} \mathrm{BM}(1: 3 w / w)$.

In 2011, Tang et al. [70] designed a series of asymmetric $\mathrm{D}_{1}-\mathrm{A}-\mathrm{D}_{2}$ OSM donor materials $23 \mathbf{a}-\mathrm{c}$ based on TPA as the $\mathrm{D}_{1}$ units, oligothiophenes $(5 \mathrm{Th})$ as the $\mathrm{D}_{2}$ units and 4,7-di(thiophen-2-yl)benzo-[1,2,5]thiadiazole (DBT) as the A units. PBE0/6-31G(d,p) and TD-PBE0/6-31pG(d,p) calculation showed asymmetric topology structure of $\mathrm{D}_{1}-\mathrm{A}-\mathrm{D}_{2}$ with vinyl linkage and $-\mathrm{NO}_{2}$ groups is a rational strategy to reduce the energy band values between HOMO and LUMO level, intensify absorption spectrum, and improve the charge transfer ability.

It is worth nothing that phenylacrylonitrile as a kind of special $\pi$-bridges with cyano groups anchoring on double bond will lead to a deep HOMO level. Thus a high $V_{\mathrm{OC}}$ will be obtained due to the strong electron-withdrawing of cyano groups.

In 2012, our research group [71] reported two D- $\pi-A$ $\pi$-D structured OSMs 24a and 24b. Both employed BT as the acceptor units, TPA as the donor units, phenylacrylonitrile or styrene as the $\pi$-bridges, respectively. As shown in Fig. 6 , with the $\pi$-bridge of styrene, the rigidity and coplanarity of the molecular backbone impart a narrow band gap of $1.92 \mathrm{eV}$ to $\mathbf{2 4 \mathbf { b }}$. Owing to cyano group anchoring on the $\pi$-bridge, 24a received a deep-lying HOMO level, which guaranteed a high $V_{\mathrm{OC}}$ of $1.04 \mathrm{~V}$ of the $\mathrm{BHJ}$ devices. The value of PCE is $3.85 \%$ and $1.99 \%$ for $\mathbf{2 4 a}$ and $\mathbf{2 4 b}$, respectively. Recently, a higher PCE (3.40\% for $\mathbf{2 4 b}$ and $4.84 \%$ for 24a) were obtained through device optimization [72]. Especially device based on 24a showed a high $V_{\text {OC }}$ of $1.08 \mathrm{~V}$.

A series of $D-\pi-A-\pi$-D typed OSMs $25 \mathbf{a}-\mathbf{d}$ based on diketopyrrolopyrrole (DPP) as the acceptor groups, TPA as the donor units were demonstrated by our research group [73]. Single bond, vinylene, acetylene and acrylonitrile were

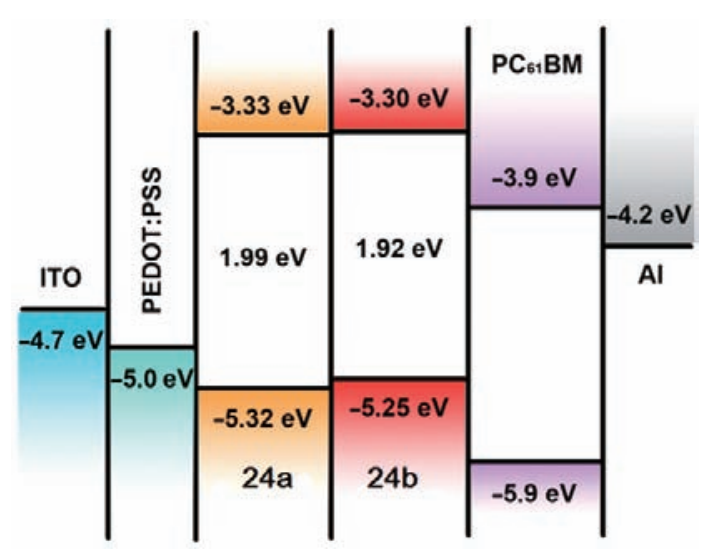

Figure 6 Schematic energy-level diagram of $\mathbf{2 4 a}$ and $\mathbf{2 4 b}$ for BHJ solar cells. integrated into $\mathbf{2 5 a}-\mathbf{d}$ as the $\pi$-bridge respectively. Benefited from rigidity, better coplanarity and strong intermolecular interaction of vinylene, $\mathbf{2 5 b}$ exhibited the highest hole mobility values $\left(2.68 \times 10^{-4} \mathrm{~cm}^{2} \mathrm{~V}^{-1} \mathrm{~s}^{-1}\right)$, which is about 2 times and 6 times higher than $25 \mathrm{c}$ and 25d. As a result, 25b reached a relatively higher PCE of 3.76\% with $J_{\mathrm{SC}}$ of $11.90 \mathrm{~mA} \mathrm{~cm}^{-2}, V_{\mathrm{OC}}$ of $0.84 \mathrm{~V}$ and $F F$ of 0.38 . Fig. 7 showed the device structure, dihedral angles, $J$ - $V$ curves of the devices and the hole mobility properties. The relatively higher $V_{\mathrm{OC}}$ values of $\mathbf{2 5 d}$ were resulted from the deep-lying HOMO energy level caused by the acrylonitrile linkage groups with the electron-withdrawing effect, increasing the oxidation potential.

\section{$\pi$-LINKAGE WITH ALKYNE}

Due to the efficient protocols for palladium catalyzed Sonogashira coupling reactions, an increasing attention has focused on triple-bond containing systems in the past few years [74-77]. Steric and conformational constraints are more accommodating when alkyne was employed as the $\pi$-linkage. Although delocalization and charge stabilization are relatively weak, the conjugation will be maintained due to their rigid rod-like structures. Besides, OSMs will receive high $V_{\mathrm{OC}}$ which were benefited from the deep-lying HOMO level caused by the electron-withdrawing effect of alkyne. Hence, alkyne including acetylene and arylacetylenes is a promising class of $\pi$-bridge [78-83]. Fig. 8 shows the chemical structures of OSM donors employing alkyne as the $\pi$-bridge and their device parameters are shown in Table 3.

In 2009, Marrocchi et al. [84] reported a series of anthracene-based derivatives $\mathbf{2 6 a - d}$. It was found that the replacement of the acetylenic for the olefinic as the $\pi$-bridge leads to a considerable increases in PV performance. Owing to the electron-withdrawing character of triple-bond, the LUMO energy levels for acetylenic compounds are lower than those olefinic analogues. The optical absorption spectra of the acetylenic/PCBM films are significantly broader than those containing olefinic/PCBM. As a consequence, the PCE of OSCs fabricated with acetylenic donors are higher than those with olefinic donors $(0.04 \%, 0.34 \%$, $1.02 \%$ and $1.17 \%$ for $\mathbf{2 6 a - d}$, respectively).

Two DPP-based OSMs 27a and 27b were demonstrated by $\mathrm{Wu}$ et al. [85] with acetylene as the $\pi$-bridge, phenanthrene as the terminal moiety in 2011. Incorporating the $\mathrm{C} \equiv \mathrm{C}$ triple bond in the molecule not only stiffen the molecular structure, avoid the steric hindrance between DPP and phenanthrene but also increase the intermolecular charge transport and the crystallinity of the active layer, giving rise 
a
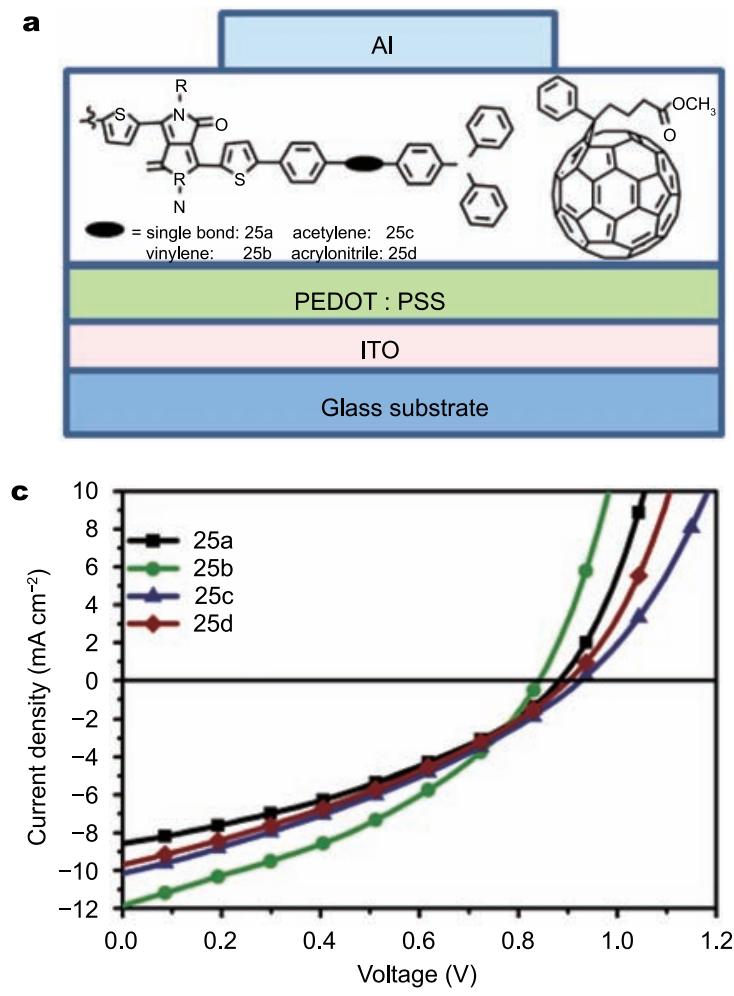

b

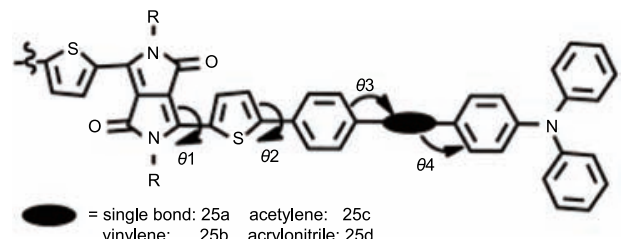

$=$ single bond: $25 \mathrm{a}$ acetylene: $25 \mathrm{c}$
vinylene: $25 \mathrm{~b}$ acrylonitrile: $25 \mathrm{~d}$

\begin{tabular}{|c|c|c|c|c|}
\hline \multirow{2}{*}{ Molecule } & \multicolumn{4}{|c|}{ Dihedral angles $\theta\left(^{\circ}\right)$} \\
\cline { 2 - 5 } & $\theta 1$ & $\theta 2$ & $\theta 2$ & $\theta 3$ \\
\hline $25 \mathrm{a}$ & 17.34 & 22.13 & 34.03 & 34.03 \\
\hline $25 \mathrm{~b}$ & 14.73 & 18.75 & 7.19 & 8.00 \\
\hline $25 \mathrm{c}$ & 16.52 & 18.36 & 18.20 & 23.69 \\
\hline 25d & 15.81 & 20.55 & 24.74 & 4.10 \\
\hline
\end{tabular}

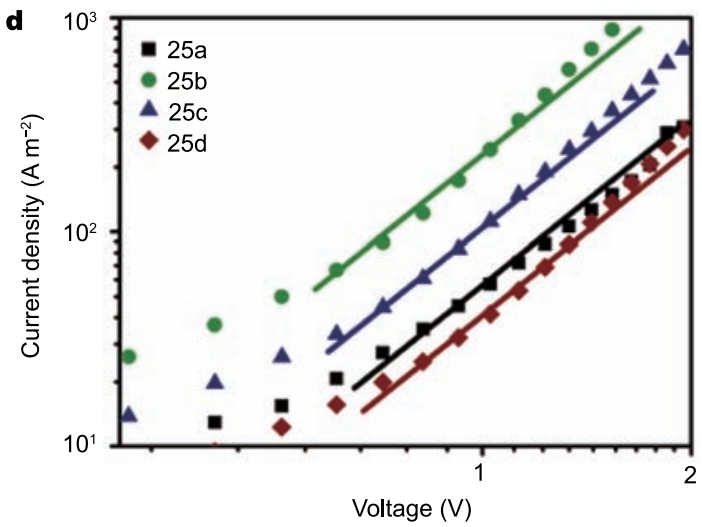

Figure 7 (a) The device structure of 25a-d; (b) dihedral angles of 25a-d optimized at the B3LYP/6-31G (d) level; (c) $J$ - $V$ curves of the devices ; (d) $J$ - $V$ curves of the hole-only devices in a double logarithmic scale. The solid lines are fits of the data points to a SCLC model.

to a better PV performance of the OSCs. As a consequence, the DPP with acetylene functionalized affords a higher PCE of $1.71 \%$ under AM $1.5 \mathrm{G}$ illumination $\left(100 \mathrm{~mA} \mathrm{~cm}^{-2}\right)$.

Two monodispersed donor molecules 28a and 28b were exhibited by Grisorio and co-workers in 2012 [86]. Both of them employed acetylene as the linker to connect dithienopyrrole (D) units and anthracene (A) units. The potential of ethynylene spacers in connection with a rigid and electron-rich central core, facilitates the planarization of the corresponding molecules with low absorption band-gap, $\pi-\pi$ stacking and high carrier mobility. As a consequence, the best PCE ( $0.34 \%$ for $\mathbf{2 8 a}, 0.95 \%$ for $\mathbf{2 8 b}$ ) were obtained from blend donor materials with $\mathrm{PC}_{61} \mathrm{BM}$ at a ratio of 40:60 $(w / w)$. In order to improve the device PV performance, Grisorio et al. using $\mathbf{2 8 b}$ as the donor and $\mathrm{PC}_{71} \mathrm{BM}$ as the acceptor. Finally, a remarkably increased PCE of $1.3 \%$ was obtained. It is worth noting that $\mathbf{2 8 b}$ ranks among the highest reported for OSM-based $\mathrm{BHJ}$ solar cells without device optimization by the year of 2012 .

To investigate the $\pi$-linkage effect of acetylene, acetylenebridged D-A-D typed OSMs 29a and 29b bearing pyrene donor units and DPP acceptor units were reported by Mun and co-workers in 2013 [87].

Acetylene incorporated molecules exhibited planar backbone, conjugation extension, smaller band gap, enhanced light absorption, lower HOMO level and higher thermal stability. Along with those advanced properties, solutionprocessed devices based on 29b produced a best PCE of $3.15 \%$ with $J_{\mathrm{SC}}$ of $8.89 \mathrm{~mA} \mathrm{~cm}{ }^{-2}, V_{\mathrm{OC}}$ of $0.85 \mathrm{~V}$ and $F F$ of 0.417 .

In 2014, our research group [72] demonstrated two similar OSMs 30a and 30b both of which employed 5,6-bis(octyloxy)benzo[c] $[1,2,5]$ thiadiazole (DOBT) as the electron-withdrawing units and TPA as the electron-donating units. Benzene and ethynylbenzene as the $\pi$-bridges were introduced in 30a and 30b, respectively. Benefited from the electron-withdrawing effect of ethynylbenzene, the devices based on 30b possessed a higher $V_{\mathrm{OC}}$ of $1.03 \mathrm{~V}$. It is interesting to note that better PCE value of $2.99 \%$ was obtained from $30 \mathrm{a}$ compared with $2.03 \%$ of $\mathbf{3 0 b}$ due to a higher $J_{\mathrm{SC}}$ ( $9.68 v$ vs. $6.56 \mathrm{~mA} \mathrm{~cm}^{-2}$ ) owned by $30 \mathrm{a}$. In the same year, we also reported a kind of OSM $25 \mathrm{c}$ introducing acetylene as the $\pi$-bridge [73]. The PV devices based on $25 \mathrm{c}$ gave a PCE of $3.10 \%$, with $J_{S C}$ of $10.30 \mathrm{~mA} \mathrm{~cm}^{-2}, V_{\mathrm{OC}}$ of $0.93 \mathrm{~V}$ 


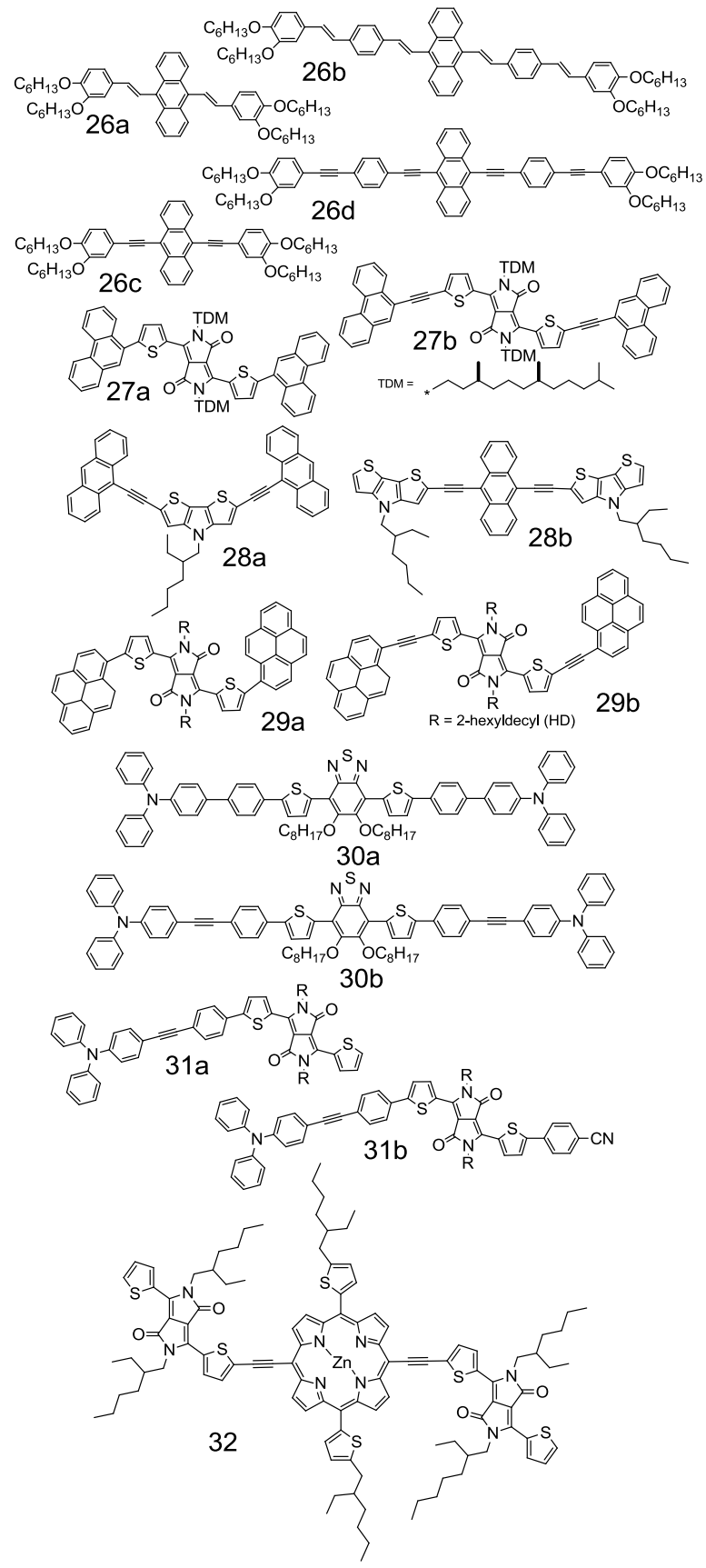

Figure 8 Chemical structures of compounds using alkyne as $\pi$ - bridge.

and $F F$ of 0.32 . The High $V_{\mathrm{OC}}$ of $0.93 \mathrm{~V}$ were attributed to the deep-lying HOMO energy levels caused by the acetylene linkage groups with the electron-withdrawing effect as well. These results indicate that triple-bond as a kind of conjugation bridge is a great candidate for OSMs realizing high $V_{\mathrm{OC}}$ value.

Recently, our research group [88] reported two asymmetrical push-pull-structure OSMs $31 \mathbf{a}$ and $\mathbf{3 1} \mathbf{b}$, which possess the prototypical structure of a D- $\pi$-A. Both of the OSMs using TPA and DPP as a fundamental dipolar D- $\pi$-A structure with ethynylbenzene as the $\pi$-bridge. Owing to the electron-withdrawing effect of $\pi$-bridge of ethynylbenzene, devices based on 31a and 31b exhibited high $V_{\mathrm{OC}}$ up to 0.97 and $0.93 \mathrm{~V}$, respectively. It is worth noting that $31 \mathbf{b}$ exhibits a remarkable PCE of 5.94\% with high $V_{\mathrm{OC}}$ of $0.93 \mathrm{~V}$, $J_{\mathrm{SC}}$ of $14.86 \mathrm{~mA} \mathrm{~cm}^{-2}, F F$ of 0.43 without any device optimization. The results indicate that ethynylbenzene as the conjugating bridge is crucial for the high PV performance of device.

The most successful push-pull-structure donor materials employing ethynylbenzene as $\pi$-bridges were obtained by Peng et al. [89]. They designed the molecule named 32 with a porphyrin ring linked to two DPP units by ethynylene bridges. The BHJ-OSCs gave high PCE of $8.08 \%$ with high $V_{\mathrm{OC}}$ of $0.78 \mathrm{~V}$, $J_{\mathrm{SC}}$ of $16.76 \mathrm{~mA} \mathrm{~cm}^{-2}$ and $F F$ of 0.618 . Due to the more s-orbital components of ethynylene, the sp-hybridization can lower the HOMO energy level of the whole molecule. Furthermore the cylinder-like $\pi$-electron density of ethynylene is more adaptable to conformational and steric constraints, thus enhancing intermolecular $\pi-\pi$ stacking and facilitating ICT.

\section{$\pi$-LINKAGE WITH ARENE AND HETEROCYCLE}

In contrast to thiophene, arene such as phenyl and anthracene, heterocycle such as fluorene and furan are another kind of considerable $\pi$-bridges applied to OSMs. Arene and heterocycle $\pi$-bridges exhibit an excellent coplanarity, and such planar configuration endowed OSMs with an efficient D-A coactions, ensuring a strong ICT absorption band for efficiently light-harvesting and possessing low-lying HOMO energy level for high $V_{\mathrm{OC}}$ [90]. Fig. 9 shows the chemical structures of OSM donors employing arene and heterocycle as bridge and Table 3 provides a summary of their device parameters.

In 2009, Mikroyannidis and co-workers [91] reported two novel OSMs 33a and 33b both with dihexyloxy-pphenylenevinylene core and cyano-vinylene nitrophenyl electron-withdrawing side groups. 33a and 33b with bridges of anthracene and thiophene respectively, showed broad absorption from 300 to $750 \mathrm{~nm}$ and narrow optical band gap $\sim 1.70 \mathrm{eV}$, indicating the efficient conjugation between the molecule backbones at the solid state. The OSCs fabricated using 33a as the donor and PCBM as the acceptor, resulting in a better PCE of $2.49 \%$ with thermal-annealling.

An unsymmetrical push-pull-structure OSM 34 comprising of TPA electron donating, dithiophene-pyrrole 


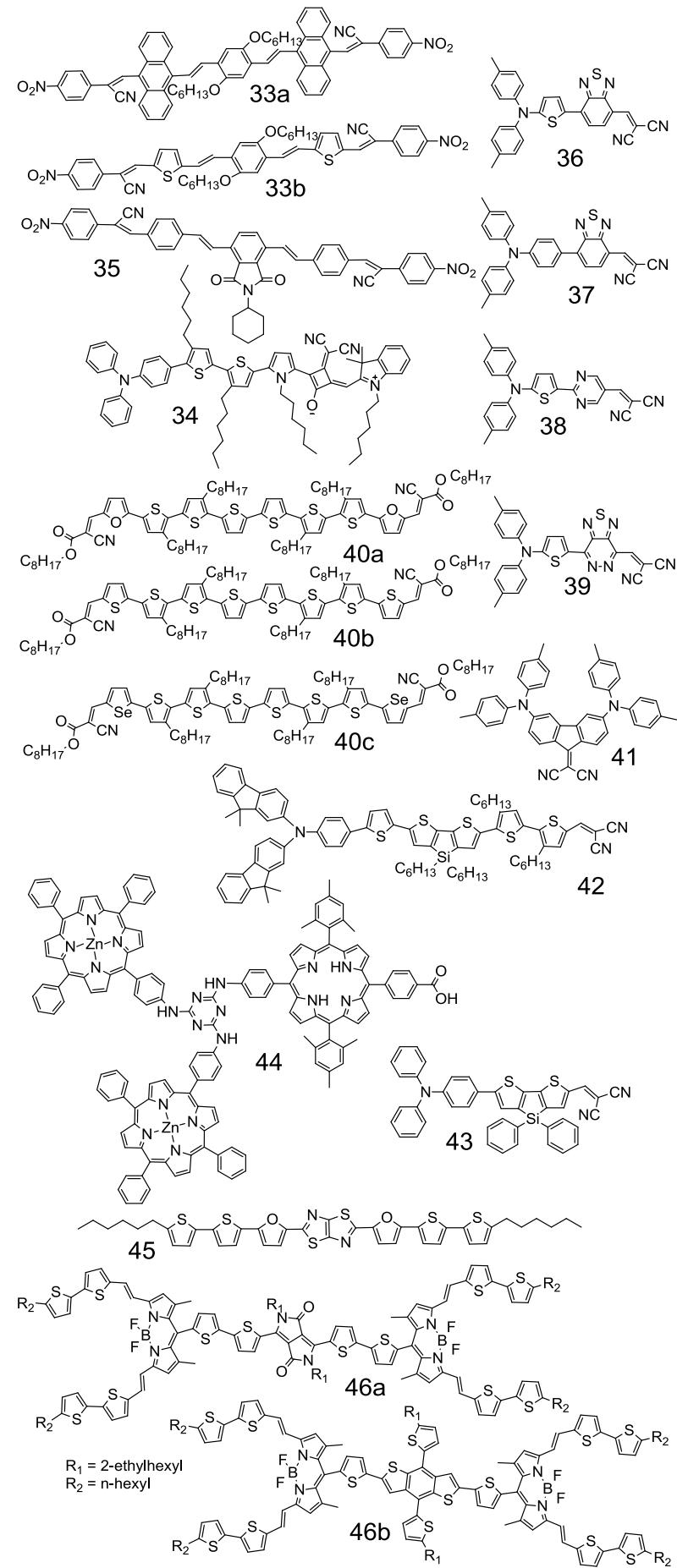

Figure 9 Chemical structures of compounds using arene and heterocycle as $\pi$-bridge.

$\pi$-bridge, and squaraine-indol electron with-drawing subunit, was reported by So et al. [92] in 2012. Benefited from its strong ICT in solution as well as in solid-state, the absorption spectrum of the compound was extended to vis- ible region. The $\mathrm{BHJ}$ device fabricated with $34 / \mathrm{PC}_{71} \mathrm{BM}$ demonstrated a PCE of $2.05 \%$ corresponding to $J_{\mathrm{SC}}$ of 9.05 $\mathrm{mA} \mathrm{cm}{ }^{-2}, V_{\mathrm{OC}}$ of $0.69 \mathrm{~V}$ and $F F$ of 0.33 .

Also in 2012, Sharma and co-workers [93] demonstrated a novel A- $\pi$-A typed OSM donor 35 based on 2-(4-nitrophenyl) acrylonitrile as the acceptor units, phthalimide and styryl units as the $\pi$-conjugation bridges. Owing to phthalimide and styryl bridges, which could also act as the donor units, an efficient ICT was achieved and the optical band gap was reduced to $1.63 \mathrm{eV}$ as well. The BHJ-OSC was fabricated based on this OSM as the donor, PCBM as the acceptor. A higher PCE ( $2.56 \%$ vs. $1.70 \%$, respectively) was achieved when used $\mathrm{PC}_{70} \mathrm{BM}$ as the acceptor. To enhance $\mathrm{PV}$ performance, Sharma and co-workers replaced tetrahydrofuran (THF) by THF-DIO (1,8-diiodooctane) as solvent and the device was also treated with thermal annealing. As a result, the best PCE of $4.14 \%$ was achieved.

A novel D-A-A typed OSM donor 36 was reported by Lin and co-workers [94] for the first time in 2011. 36 owns ditolylaminothienyl electron-donating moiety, dicyanovinylene electron-withdrawing moiety, and the dipolar units were bridged by an electron-deficient 2,1,3-benzothiadiazole (BT) segment. The most ubiquitous acceptor unit BT employed as connection here exhibited fascinating features, including low-band-gap character, high absorption coefficient, and appropriate energy levels. Vacuum-deposited OSC based on $\mathbf{3 6}$ donor and $\mathrm{C}_{70}$ acceptor achieved a record-high PCE of $5.81 \%$. This efficiency is among the highest for organic vacuum-deposited single cells at that time. Soon after in 2012 [95], they designed and synthesized 37, which replaces the thiophene subunit with benzene subunit within donor unit. By delicate device optimizations including fine-tuning the thicknesses of active layer and the blended D:A ratio, vacuum-deposited devices based on 37 and $C_{70}$ possessed a best PCE of $6.8 \%$ under AM1.5G simulated solar illumination. In the same year, $\mathbf{3 8}$ possessing of D-A-A molecular architecture were also showed by their group [96]. Compared with 36, 38 features electron-deficient pyrimidine as bridge to connect the ditolylaminothienyl electron-donating moiety and dicyanovinylene electron-withdrawing moiety. A nearly coplanar conformation of $\mathbf{3 8}$ ensured a close-knit stacking in the solid state, thus realizing high extinction coefficients throughout the spectral coverage. As a consequence, vacuum-deposited devices with $\mathrm{C}_{70}$ as the acceptor, giving a PCE as high as $6.4 \%$.

Wang et al. [97] theoretically designed a series of D-A-A structured OSMs derived from the $\mathbf{3 7}$ with different heterocyclic bridges such as thiadiazolopyridazine, oxadiazolopy- 
Table 3 Device parameters of compounds using alkene, alkyne, arene and heterocycle as $\pi$-linkage

\begin{tabular}{|c|c|c|c|c|c|c|c|}
\hline Compound & $\pi$-bridge & $J_{\mathrm{SC}}\left(\mathrm{mA} \mathrm{cm}^{-2}\right)$ & $V_{\mathrm{OC}}(\mathrm{V})$ & FF & PCE (\%) & Device optimization & Ref. \\
\hline 22 & Vinylene & 8.58 & 0.85 & 0.327 & 2.39 & 1 & [69] \\
\hline $23 a$ & l & l & l & l & l & l & \multirow{3}{*}[70]{} \\
\hline $23 b$ & Vinylene & l & / & l & l & l & \\
\hline $23 c$ & Vinylene & l & l & l & I & l & \\
\hline $24 a$ & Phenylacrylonitrile & 14.0 & 1.08 & 0.32 & 4.84 & $\mathrm{D} / \mathrm{A}$ radio & {$[72]$} \\
\hline $24 b$ & Styrene & 8.77 & 0.92 & 0.42 & 3.40 & $\mathrm{D} / \mathrm{A}$ radio & {$[71]$} \\
\hline $25 a$ & Single bond & 8.62 & 0.88 & 0.36 & 2.74 & l & \multirow{4}{*}{ [73] } \\
\hline $25 b$ & Vinylene & 11.90 & 0.84 & 0.38 & 3.76 & l & \\
\hline $25 c$ & Acetylene & 10.30 & 0.93 & 0.32 & 3.10 & l & \\
\hline $25 d$ & Acrylonitrile & 9.73 & 0.90 & 0.33 & 2.92 & l & \\
\hline $26 a$ & Olefince & 0.26 & 0.79 & 0.20 & 0.04 & $\mathrm{D} / \mathrm{A}$ radio & \multirow{4}{*}{ [84] } \\
\hline $26 b$ & Olefince & 1.16 & 0.88 & 0.32 & 0.34 & $\mathrm{D} / \mathrm{A}$ radio & \\
\hline $26 c$ & Acetylence & 2.62 & 0.96 & 0.45 & 1.17 & $\mathrm{D} / \mathrm{A}$ radio & \\
\hline 26d & Acetylence & 2.63 & 0.93 & 0.41 & 1.02 & $\mathrm{D} / \mathrm{A}$ radio & \\
\hline $27 a$ & $\mathrm{C}-\mathrm{C}$ single bond & 2.79 & 0.92 & 0.27 & 0.69 & TA $100^{\circ} \mathrm{C}$ & \multirow{2}{*}[85]{} \\
\hline $27 b$ & $\mathrm{C} \equiv \mathrm{C}$ triple bond & 3.92 & 0.77 & 0.57 & 1.71 & $\mathrm{TA} 100^{\circ} \mathrm{C}$ & \\
\hline $28 \mathrm{a}$ & Acetylene & 3.07 & 0.36 & 0.31 & 0.34 & l & \multirow{2}{*}[86]{} \\
\hline $28 b$ & Acetylene & 6.03 & 0.70 & 0.31 & 1.3 & Acceptor material & \\
\hline $29 a$ & Acetylene & 2.38 & 0.79 & 0.272 & 0.51 & l & \multirow{2}{*}{ [87] } \\
\hline $29 b$ & Acetylene & 8.89 & 0.85 & 0.417 & 3.15 & I & \\
\hline $30 \mathrm{a}$ & Benzene & 9.68 & 0.94 & 0.33 & 2.99 & l & \multirow{2}{*}[72]{} \\
\hline $30 b$ & Ethynylbenzene & 6.56 & 1.03 & 0.30 & 2.03 & l & \\
\hline $31 a$ & Ethynylbenzene & 7.07 & 0.97 & 0.30 & 2.06 & l & \multirow{2}{*}{ [88] } \\
\hline $31 b$ & Ethynylbenzene & 14.86 & 0.93 & 0.43 & 5.94 & l & \\
\hline 32 & Ethynylene & 16.76 & 0.78 & 0.618 & 8.08 & $\begin{array}{c}\mathrm{TA} 120^{\circ} \mathrm{C} 1 \% \\
\text { pyridine additive }\end{array}$ & {$[89]$} \\
\hline $33 a$ & Anthracene & 5.30 & 0.87 & 0.54 & 2.49 & $\mathrm{TA} 100^{\circ} \mathrm{C}$ & \multirow{2}{*}[91]{} \\
\hline $33 b$ & Thiophene & 5.16 & 0.85 & 0.53 & 2.33 & TA $100^{\circ} \mathrm{C}$ & \\
\hline 34 & Dithiophene-pyrrole & 9.05 & 0.69 & 0.33 & 2.05 & l & {$[92]$} \\
\hline 35 & Phthalimide and styryl & 8.8 & 0.84 & 0.56 & 4.14 & $\begin{array}{c}\text { TA } 110^{\circ} \mathrm{C} \\
\text { DIO Additive }\end{array}$ & {$[93]$} \\
\hline 36 & Benzothiadiazole & 14.68 & 0.79 & 0.50 & 5.81 & $\begin{array}{l}\text { Active and } \mathrm{MoO}_{x} \\
\text { layer thickness }\end{array}$ & {$[94]$} \\
\hline 37 & Benzothiadiazole & 13.48 & 0.93 & 0.53 & 6.8 & $\begin{array}{c}\text { D/A radio } \\
\text { Active layer thickness }\end{array}$ & {$[95]$} \\
\hline 38 & Pyrimidine & 12.1 & 0.95 & 0.56 & 6.4 & Active layer thickness & {$[96]$} \\
\hline 39 & Thiadiazolopyridazine & l & l & l & l & l & {$[97]$} \\
\hline $40 a$ & Furan & 6.34 & 0.78 & 0.643 & 3.18 & l & \multirow{3}{*}{ [98] } \\
\hline $40 \mathrm{~b}$ & Thiophene & 7.43 & 0.85 & 0.716 & 4.52 & l & \\
\hline $40 c$ & Selenophene & 10.97 & 0.85 & 0.671 & 6.15 & l & \\
\hline 41 & Fluorene & 7.64 & 0.99 & 0.53 & 4.04 & l & \multirow{2}{*}{ [99] } \\
\hline 41 & Fluorene & 5.00 & 1.92 & 0.55 & 5.31 & Tandem-cell & \\
\hline 42 & Thiophenedithienosiole & 7.31 & 0.81 & 0.40 & 2.34 & $\begin{array}{l}\mathrm{TiO}_{x} \text { layer } \mathrm{D} / \mathrm{A} \text { radio } \\
\text { Active layer thickness }\end{array}$ & {$[100]$} \\
\hline 43 & Dithienosiole derivative & 9.53 & 0.83 & 0.48 & 3.82 & l & {$[101]$} \\
\hline 44 & Triazine & 8.06 & 0.92 & 0.53 & 3.93 & $\begin{array}{c}\text { 1-CN additive } \mathrm{D} / \mathrm{A} \\
\text { radio }\end{array}$ & {$[102]$} \\
\hline 45 & Furan & 10.13 & 0.756 & 0.34 & 2.72 & $\mathrm{D} / \mathrm{A}$ radio & {$[103]$} \\
\hline $46 a$ & Diketopyrrolopyrrole derivative & 13.39 & 0.73 & 0.373 & 3.62 & l & \multirow{2}{*}[104]{} \\
\hline $46 b$ & Benzodithiophene derivative & 7.76 & 0.76 & 0.356 & 2.10 & l & \\
\hline
\end{tabular}


ridazine and thiadiazolopyridine in 2014. Calculations indicate that $\mathbf{3 9}$ employing thiadiazolopyridazine as the bridge possesses lower HOMO energy level, better light absorption, more favorable exciton dissociation and hole transport, facilitating the PV performance.

In 2013, Liu et al. [98] reported three solution-processed OSMs 40a-c with heterocycle furan, thiophene and selenophene as the linkers respectively. The results reveal that the energy level as well as the optical energy gap can be fine-tuned through modification with various electron linkers. Device based on these molecules exhibited high PCEs, ranging from $3.18 \%$ to $6.15 \%$. A highest PCE of $6.15 \%$ along with $V_{\mathrm{OC}}$ of $0.85 \mathrm{~V}, J_{\mathrm{SC}}$ of $10.79 \mathrm{~mA} \mathrm{~cm}-2$ and a notable $F F$ of $67.1 \%$ were acquired by using $40 \mathrm{c}$ and $\mathrm{PC}_{71} \mathrm{BM}$ blend $(1: 1.2 w / w)$. This result demonstrates that selenophene unit can be profitably employed as a $\pi$-bridge, which is even more efficient and steady than thiophene unit as well as furan in this system. Fluorene used as the $\pi$-linker was demonstrated by Chi et al. [99] also in 2013. They synthesized an OSM donor material 41 in which two diptolylamino donor units and a dicyanovinylene acceptor unit were linked by a planar and rigid fluorene. Such molecular configuration not only reduced the distance between the donor and acceptor but also increased the molecular rigidity. Vacuum-deposited single-cell devices based on 41 and $\mathrm{C}_{70}$ showed a high PCE of $4.04 \%$. In addition, a tandem cell improved the PCE up to $5.31 \%$.

A new molecule 42 employing $\pi$-conjugated thiophene incorporating dithienosiole unit as the bridge was demonstrated by Paek et al. [100] in 2014. The best material with thiophene dithienosiole bridge was obtained from backbone structure of bis(9,9-dimethyl-9H-fluoren-2-yl)aniline as the donor and methylene malononitrile as the acceptor, yielding a $J_{\mathrm{SC}}$ of $7.31 \mathrm{~mA} \mathrm{~cm} \mathrm{~cm}^{-2}, V_{\mathrm{OC}}$ of $0.81 \mathrm{~V}, F F$ of 0.40 , and PCE of $2.34 \%$ with an optimized device. Moreover, dithienosiole derivatives employed as the bridge was also exhibited by Lin et al. [101]. They reported a new $D-\pi$-A molecule 43 , which adopted coplanar diphenyl-substituted dithienosilole as a central $\pi$-bridge. The adoption of D- $\pi$-A structure with a coplanar bridge not only facilitates the electronic coupling between the donor and acceptor blocks, but also extends the spectral response to the red region. BHJ device based on 43: $\mathrm{C}_{70}$ showed a PCE of $3.82 \%$ with $J_{\mathrm{SC}}$ of $9.53 \mathrm{~mA} \mathrm{~cm}{ }^{-2}, V_{\mathrm{OC}}$ of $0.83 \mathrm{~V}, F F$ of 0.48 .

Triazine is a heterocyclic aromatic with strong electron withdrawing properties which was often employed as conjugation bridges [105-107] or electrophilic core [108-112] in optoelectronic materials. Very recently, Sharma et al.
[102] also demonstrated a triazine-bridged donor material $\mathbf{4 4}$ with the D- $\pi$-A molecular architecture. $\mathbf{4 4}$ consisted of two zinc-metalated units and one free-base unit. A PCE value of $2.85 \%$ was achieved for solution-processed $\mathrm{BHJ}$ device based on $\mathbf{4 4}$ and $\mathrm{PC}_{70} \mathrm{BM}$. Efficiency of the device was finally improved to $3.93 \%$ due to the $5 \%$ of 1 -chloronaphathalene $(\mathrm{CN})$ as solvent additive incorporated in THF.

Novel furan-bridged thiazolo $[5,4-d]$ thiazole based $\pi$-conjugated small molecule $\mathbf{4 5}$ was formulated by Shin et al. [103]. The presence of furan bridge along with two terminal alkyl units improved the absorption and solubility properties significantly. Finally, the SM-OSCs based on 45 present a relatively high PCE of $2.72 \%$, which might be attributed to the improved absorption, electrochemical properties and the presence of strong electron-withdrawing of furan moieties.

Zhan et al. [104] reported the use of a DPP instead of a 4,8-dithienyl BDT as the $\pi$-bridge in the BODIPY dimer 46a and 46b. The absorption and its crystallinity can be efficiently controlled by simply using a DPP instead of a 4,8-dithienyl BDT as the $\pi$-bridge. As a result, a 1.7 -fold increase of the $J_{\mathrm{SC}}$ from 7.8 to $13.4 \mathrm{~mA} \mathrm{~cm}{ }^{-2}$ is caused by 1.07-time enhancement of the absorption. Hence, the PCE value was enhanced from $2.1 \%$ to $3.6 \%$, which is the second highest PCE for BODIPY-based organic solar cells so far.

\section{CONCLUSIONS}

In this review, we have systematically summarized the four classes of $\pi$-bridges and their linkage effect of push-pullstructure OSMs. A few conclusions can be acquired from individual classes of materials. To begin with, thiophene and its derivatives not only have a high charge transport property in the $\mathrm{D}$-A backbone, but also increase the degree of conjugation of the molecules. High charge transport property ensures an efficient ICT and sufficiently longer conjugation degree provides a higher molar absorptivity. Then alkene (such as vinylene, styrene and phenylacrylonitrile) with strict rigidity and coplanarity, the molecule backbone possesses a better delocalization and charge stabilization. Especially the phenylacrylonitrile with cyano group anchoring on double bond, will achieve a low-lying HOMO level and high $V_{\mathrm{OC}}$ for devices. Furthermore, when alkyne (such as acetylene or arylacetylenes) is employed as the $\pi$-linkage, steric and conformational constraint is more accommodating but conjugation will be maintained due to their rigid rod-like structures. OSMs will achieve a high $V_{\text {OC }}$ benefited from the deep-lying HOMO level caused by the electron-withdrawing effect of alkyne. Finally, heterocyclic arene (such as phenyl, anthracene, phthalimide etc.) 
exhibit excellent coplanarity, and such planar configuration endow OSMs with an efficient D-A coactions, ensuring a strong ICT absorption band for efficiently light-harvesting. Those conclusions may indicate that in order to yield high performance devices, new donor materials must be developed, and the proper bridges are critical for designing some optimized molecules. Overall, with judicious and careful molecule design, we undoubtedly believe that SM-OSCs will achieve high efficiency and realize the commercial application in the near future. But before that an further study of the $\pi$-linkage effect is still a great challenge for us to deal with.

Received 12 April 2016; accepted 19 May 2016; published online 31 May 2016

1 Chu S, Majumdar A. Opportunities and challenges for a sustainable energy future. Nature, 2012, 488: 294-303

2 Chow J. Energy resources and global development. Science, 2003, 302: 1528-1531

3 Turner JA. A realizable renewable energy future. Science, 1999, 285 : 687-689

4 Coughlin JE, Henson ZB, Welch GC, et al. Design and synthesis of molecular donors for solution-processed high-efficiency organic solar cells. Acc Chem Res, 2014, 47: 257-270

5 Worch JC, Chirdon DN, Maurer AB, et al. Synthetic tuning of electronic and photophysical properties of 2-aryl-1,3-benzothiaphospholes. J Org Chem, 2013, 78: 7462-7469

6 Demeter D, Rousseau T, Leriche P, et al. Manipulation of the open-circuit voltage of organic solar cells by desymmetrization of the structure of acceptor-donor-acceptor molecules. Adv Funct Mater, 2011, 21: 4379-4387

7 Peet J, Heeger AJ, Bazan GC. "Plastic" solar cells: self-assembly of bulk heterojunction nanomaterials by spontaneous phase separation. Acc Chem Res, 2009, 42: 1700-1708

8 Walker B, Kim C, Nguyen TQ. Small molecule solution-processed bulk heterojunction solar cells. Chem Mater, 2011, 23: 470-482

9 Rand BP, Genoe J, Heremans P, et al. Solar cells utilizing small molecular weight organic semiconductors. Prog Photovolt-Res Appl, 2007, 15: 659-676

10 Mazzio KA, Luscombe CK. The future of organic photovoltaics. Chem Soc Rev, 2015, 44: 78-90

11 Xu X, Kyaw AKK, Peng B, et al. A plasmonically enhanced polymer solar cell with gold-silica core-shell nanorods. Org Electron, 2013, 14: $2360-2368$

12 Kyaw AKK, Wang DH, Gupta V, et al. Intensity dependence of current-voltage characteristics and recombination in high-efficiency solution-processed small-molecule solar cells. ACS Nano, 2013, 7: 4569-4577

13 Xu X, Kyaw AKK, Peng B, et al. Enhanced efficiency of solution-processed small-molecule solar cells upon incorporation of gold nanospheres and nanorods into organic layers. Chem Commun, 2014, 50: 4451-4454

14 Wang DH, Kyaw AKK, Pouliot JR, et al. Enhanced power conversion efficiency of low band-gap polymer solar cells by insertion of optimized binary processing additives. Adv Energy Mater, 2014, 4: 1300835
15 Li Z, Pei J, Li Y, et al. Synthesis and photovoltaic properties of solution processable small molecules containing 2-pyran-4-ylidenemalononitrile and oligothiophene moieties. J Phys Chem C, 2010, 114: $18270-18278$

16 Li Z, Dong Q, Xu B, et al. Novel solution processable small molecule containing new electron-withdrawing group and oligothiophene for photovoltaic applications. Solar Energy Mater Solar Cells, 2012, 98: 343-350

17 Li Z, Bian J, Wang Y, et al. Effect of alkyl chain length on the photovoltaic performance of oligothiophene-based small molecules. Solar Energy Mater Solar Cells, 2014, 130: 336-346

18 Kan B, Li M, Zhang Q, et al. A series of simple oligomer-like small molecules based on oligothiophenes for solution-processed solar cells with high efficiency. J Am Chem Soc, 2015, 137: 3886-3893

19 Heremans P, Cheyns D, Rand BP. Strategies for increasing the efficiency of heterojunction organic solar cells: material selection and device architecture. Acc Chem Res, 2009, 42: 1740-1747

20 Huang QL, Li HX. Recent progress of bulk heterojunction solar cells based on small-molecular donors. Chin Sci Bull, 2013, 58: 2677-2685

21 Chen Y, Wan X, Long G. High performance photovoltaic applications using solution-processed small molecules. Acc Chem Res, 2013, 46: 2645-2655

22 Dutta P, Yang W, Lee WH, et al. Novel naphtho[1,2-b:5,6$b^{\prime}$ ]dithiophene core linear donor- $\pi$-acceptor conjugated small molecules with thiophene-bridged bithiazole acceptor: design, synthesis, and their application in bulk heterojunction organic solar cells. J Mater Chem, 2012, 22: 10840-10851

23 Velusamy M, Huang JH, Hsu YC, et al. Dibenzo[f,h]thieno[3,4- $b$ ] quinoxaline-based small molecules for efficient bulk-heterojunction solar cells. Org Lett, 2009, 11: 4898-4901

24 Zhen H, Liu J, Hou L, et al. Synthesis and photovoltaic properties of star-shaped triphenylamine molecules with donor-acceptor unit as core. J Mater Sci-Mater Electron, 2014, 25: 3559-3565

25 Liu Y, Wan X, Wang F, et al. Spin-coated small molecules for high performance solar cells. Adv Energy Mater, 2011, 1: 771-775

26 Liu Y, Wan X, Wang F, et al. High-performance solar cells using a solution-processed small molecule containing benzodithiophene unit. Adv Mater, 2011, 23: 5387-5391

27 Shang H, Fan H, Shi Q, et al. Solution processable D-A-D molecules based on triphenylamine for efficient organic solar cells. Solar Energy Mater Solar Cells, 2010, 94: 457-464

28 Zhang J, Wu G, He C, et al. Triphenylamine-containing D-A-D molecules with (dicyanomethylene)pyran as an acceptor unit for bulk-heterojunction organic solar cells. J Mater Chem, 2011, 21: 3768-3774

29 Shi Q, Cheng P, Li Y, et al. A solution processable D-A-D molecule based on thiazolothiazole for high performance organic solar cells. Adv Energy Mater, 2012, 2: 63-67

30 Shen S, Jiang P, He C, et al. Solution-processable organic molecule photovoltaic materials with bithienyl-benzodithiophene central unit and indenedione end groups. Chem Mater, 2013, 25: 2274-2281

31 Yin $\mathrm{N}$, Wang L, Ma Y, et al. 4,8-Bis(thienyl)-benzo[1,2-b:4,5$b^{\prime}$ ]dithiophene based A- $\pi-\mathrm{D}-\pi-\mathrm{A}$ typed conjugated small molecules with mono-thiophene as the $\pi$-bridge: Synthesis, properties and photovoltaic performance. Dyes Pigments, 2015, 120: 299-306

32 Wang JL, Yin QR, Miao JS, et al. Rational design of small molecular donor for solution-processed organic photovoltaics with $8.1 \%$ efficiency and high fill factor via multiple fluorine substituents and thiophene bridge. Adv Funct Mater, 2015, 25: 3514-3523

33 Mikroyannidis JA, Kabanakis AN, Kumar A, et al. Synthesis of a low-band-gap small molecule based on acenaphthoquinoxaline 
for efficient bulk heterojunction solar cells. Langmuir, 2010, 26: 12909-12916

34 Kim J, Cho N, Min ko H, et al. Push-pull organic semiconductors comprising of bis-dimethylfluorenyl amino benzo[b]thiophene donor and various acceptors for solution processed small molecule organic solar cells. Solar Energy Mater Solar Cells, 2012, 102: 159-166

35 Bai H, Wang Y, Cheng P, et al. Acceptor-donor-acceptor small molecules based on indacenodithiophene for efficient organic solar cells. ACS Appl Mater Interfaces, 2014, 6: 8426-8433

36 Tamayo AB, Walker B, Nguyen TQ. A low band gap, solution processable oligothiophene with a diketopyrrolopyrrole core for use in organic solar cells. J Phys Chem C, 2008, 112: 11545-11551

37 Xia PF, Feng XJ, Lu J, et al. Donor-acceptor oligothiophenes as low optical gap chromophores for photovoltaic applications. Adv Mater, 2008, 20: 4810-4815

38 Fitzner R, Reinold E, Mishra A, et al. Dicyanovinyl-substituted oligothiophenes: structure-property relationships and application in vacuum-processed small molecule organic solar cells. Adv Funct Mater, 2011, 21: 897-910

39 Xia PF, Feng XJ, Lu J, et al. Triarylamino and tricyanovinyl endcapped oligothiophenes with reduced optical gap for photovoltaic applications. J Phys Chem C, 2008, 112: 16714-16720

40 Zhang W, Tse SC, Lu J, et al. Solution processable donor-acceptor oligothiophenes for bulk-heterojunction solar cells. J Mater Chem, 2010, 20: 2182-2189

41 Zhang J, Deng D, He C, et al. Solution-processable star-shaped molecules with triphenylamine core and dicyanovinyl endgroups for organic solar cells. Chem Mater, 2011, 23: 817-822

42 Lin Y, Zhang ZG, Bai H, et al. A star-shaped oligothiophene endcapped with alkyl cyanoacetate groups for solution-processed organic solar cells. Chem Commun, 2012, 48: 9655-9657

43 Cho N, Song K, Lee JK, et al. Facile synthesis of fluorine-substituted benzothiadiazole-based organic semiconductors and their use in solution-processed small-molecule organic solar cells. Chem Eur J, 2012, 18: 11433-11439

44 Tang W, Huang D, He C, et al. Solution-processed small molecules based on indacenodithiophene for high performance thin-film transistors and organic solar cells. Org Electron, 2014, 15: 1155-1165

45 Lin Y, Cheng P, Liu Y, et al. Small molecules based on bithiazole for solution-processed organic solar cells. Org Electron, 2012, 13: 673-680

46 Cheng P, Shi Q, Lin Y, et al. Evolved structure of thiazolothiazole based small molecules towards enhanced efficiency in organic solar cells. Org Electron, 2013, 14: 599-606

47 Zhou J, Wan X, Liu Y, et al. A planar small molecule with dithienosilole core for high efficiency solution-processed organic photovoltaic cells. Chem Mater, 2011, 23: 4666-4668

48 Zhou J, Wan X, Liu Y, et al. Small molecules based on benzo[1,2$\left.b: 4,5-b^{\prime}\right]$ dithiophene unit for high-performance solution-processed organic solar cells. J Am Chem Soc, 2012, 134: 16345-16351

$49 \mathrm{Ni} \mathrm{W}$, Li M, Wan X, et al. A high-performance photovoltaic small molecule developed by modifying the chemical structure and optimizing the morphology of the active layer. RSC Adv, 2014, 4: 31977-31980

50 Kan B, Zhang Q, Liu F, et al. Small molecules based on alkyl/alkylthio-thieno $[3,2-b]$ thiophene-substituted benzo[1,2$b: 4,5-b]$ dithiophene for solution-processed solar cells with high performance. Chem Mater, 2015, 27: 8414-8423

51 Kan B, Zhang Q, Li M, et al. Solution-processed organic solar cells based on dialkylthiol-substituted benzodithiophene unit with efficiency near 10\%. J Am Chem Soc, 2014, 136: 15529-15532
52 Cui C, Guo X, Min J, et al. High-performance organic solar cells based on a small molecule with alkylthio-thienyl-conjugated side chains without extra treatments. Adv Mater, 2015, 27: 7469-7475

53 Deng D, Yang Y, Zhang J, et al. Triphenylamine-containing linear D-A-D molecules with benzothiadiazole as acceptor unit for bulkheterojunction organic solar cells. Org Electron, 2011, 12: 614-622

54 Deng D, Shen S, Zhang J, et al. Solution-processable star-shaped photovoltaic organic molecule with triphenylamine core and thieno[3,2-b]thiophene-dicyanovinyl arms. Organic Electrons, 2012, 13: 2546-2552

55 Lee JK, Lee S, Yun SJ. Effects of fused thiophene bridges in organic semiconductors for solution-processed small-molecule organic solar cells. Bull Korean Chem Soc, 2013, 34: 2148-2154

56 Lee JK, Kim J, Choi H, et al. Push-pull organic semiconductors with planar indenothiophene bridges for solution-processed small-molecule organic solar cells. Tetrahedron, 2014, 70: 6235-6240

57 Wang JL, Xiao F, Yan J, et al. Toward high performance indacenodithiophene-based small-molecule organic solar cells: investigation of the effect of fused aromatic bridges on the device performance. J Mater Chem A, 2016, 4: 2252-2262

$58 \mathrm{He}$ C, He Q, Yang X, et al. Synthesis and photovoltaic properties of a solution-processable organic molecule containing triphenylamine and DCM moieties. J Phys Chem C, 2007, 111: 8661-8666

59 Zhou Y, Peng P, Han L, et al. Novel donor-acceptor molecules as donors for bulk heterojunction solar cells. Synt Metals, 2007, 157: 502-507

60 Yang Y, Zhang J, Zhou Y, et al. Solution-processable organic molecule with triphenylamine core and two benzothiadiazole-thiophene arms for photovoltaic application. J Phys Chem C, 2010, 114: 3701-3706

61 Mikroyannidis JA, Kabanakis AN, Sharma SS, et al. Low band-gap phenylenevinylene and fluorenevinylene small molecules containing triphenylamine segments: synthesis and application in bulk heterojunction solar cells. Org Electron, 2011, 12: 774-784

62 Kylberg W, Sonar P, Heier J, et al. Synthesis, thin-film morphology, and comparative study of bulk and bilayer heterojunction organic photovoltaic devices using soluble diketopyrrolopyrrole molecules. Energy Environ Sci, 2011, 4: 3617-3624

63 Cho MJ, Seo J, Oh HS, et al. Tricyanofuran-based donor-acceptor type chromophores for bulk heterojunction organic solar cells. Solar Energy Mater Solar Cells, 2012, 98: 71-77

64 Zitzler-kunkel A, Lenze MR, Schnier T, et al. Comparative studies on optical, redox, and photovoltaic properties of a series of D-A-D and analogous D-A chromophores. Adv Funct Mater, 2014, 24: 4645-4653

65 Sharma GD, Patel KR, Roy MS, et al. Characterization of two new $(\mathrm{A}-\pi) 2-\mathrm{D}-\mathrm{A}$ type dyes with different central $\mathrm{D}$ unit and their application for dye sensitized solar cells. Org Electron, 2014, 15: 1780-1790

66 Zhao G, Wu G, He C, et al. Solution-processable multiarmed organic molecules containing triphenylamine and DCM moieties: synthesis and photovoltaic properties. J Phys Chem C, 2009, 113: 2636-2642

$67 \mathrm{He} \mathrm{C}, \mathrm{He} \mathrm{Q}$, Yi Y, et al. Improving the efficiency of solution processable organic photovoltaic devices by a star-shaped molecular geometry. J Mater Chem, 2008, 18: 4085-4090

68 Zeng S, Yin L, Jiang X, et al. D-A-D low band gap molecule containing triphenylamine and benzoxadiazole/benzothiadiazole units: synthesis and photophysical properties. Dyes Pigments, 2012, 95: 229-235

69 Zhang J, Yang Y, He C, et al. Solution-processable star-shaped photovoltaic organic molecule with triphenylamine core and benzothiadiazole-thiophene arms. Macromolecules, 2009, 42: 7619-7622 
70 Tang S, Zhang J. Rational design of organic asymmetric donors D1-A-D2 possessing broad absorption regions and suitable frontier molecular orbitals to match typical acceptors toward solar cells. J Phys Chem A, 2011, 115: 5184-5191

71 Zeng S, Yin L, Ji C, et al. D- $\pi-A-\pi-D$ type benzothiadiazole-triphenylamine based small molecules containing cyano on the $\pi$-bridge for solution-processed organic solar cells with high open-circuit voltage. Chem Commun, 2012, 48: 10627-10629

72 Wang L, Yin L, Ji C, et al. High open-circuit voltage of the solution-processed organic solar cells based on benzothiadiazole-triphenylamine small molecules incorporating $\pi$-linkage. Organic Electrons, 2014, 15: 1138-1148

73 Ji C, Yin L, Wang L, et al. Linkage effects of linear $D-\pi-A-\pi-D$ type diketopyrrolopyrrole-triphenylamine based solution-processable organic small molecule photovoltaic materials. J Mater Chem C, 2014, 2: 4019-4026

74 Valentini L, Bagnis D, Marrocchi A, et al. Novel anthracene-core molecule for the development of efficient pcbm-based solar cells. Chem Mater, 2008, 20: 32-34

75 Wang H, Lim HS, Kim S, et al. Oliogothiophenes end-capped with arylacetylenes for organic thin film transistors. Synt Metals, 2009, 159: 2564-2570

76 Marrocchi A, Spalletti A, Ciorba S, et al. Synthesis and photophysical properties of conjugated anthracene-based compounds. J Photochem Photobiol A Chem, 2010, 211: 162-169

77 Seri M, Marrocchi A, Bagnis D, et al. Molecular-shape-controlled photovoltaic performance probed via soluble $\pi$-conjugated arylacetylenic semiconductors. Adv Mater, 2011, 23: 3827-3831

78 Valentini L, Marrocchi A, Seri M, et al. [2.2]Paracyclophane-based molecular systems for the development of organic solar cells. Thin Solid Films, 2008, 516: 7193-7198

79 Silvestri F, Marrocchi A, Seri M, et al. Solution-processable low-molecular weight extended arylacetylenes: versatile p-type semiconductors for field-effect transistors and bulk heterojunction solar cells. J Am Chem Soc, 2010, 132: 6108-6123

80 Flamini R, Tomasi I, Marrocchi A, et al. Synthesis and photobehaviour of donor- $\pi$-acceptor conjugated arylacetylenes. J Photochem Photobiol A Chem, 2011, 223: 140-148

81 Zhao X, Ma L, Zhang L, et al. An acetylene-containing perylene diimide copolymer for high mobility n-channel transistor in air. Macromolecules, 2013, 46: 2152-2158

82 Braunecker WA, Oosterhout SD, Owczarczyk ZR, et al. Ethynylene-linked donor-acceptor alternating copolymers. Macromolecules, 2013, 46: 3367-3375

83 Flamini R, Marrocchi A, Spalletti A. Quantitative cascade energy transfer in semiconductor thin films. Photochem Photobiol Sci, 2014, 13: 1031-1038

84 Marrocchi A, Silvestri F, Seri M, et al. Conjugated anthracene derivatives as donor materials for bulk heterojunction solar cells: olefinic versus acetylenic spacers. Chem Commun, 2009, 1380-1382

85 Wu Z, Li A, Fan B, et al. Phenanthrene-functionalized 3,6-dithiophen-2-yl-2,5- dihydropyrrolo[3,4-c]pyrrole-1,4-diones as donor molecules for solution-processed organic photovoltaic cells. Solar Energy Mater Solar Cells, 2011, 95: 2516-2523

86 Grisorio R, Allegretta G, Suranna GP, et al. Monodispersed vs. polydispersed systems for bulk heterojunction solar cells: the case of dithienopyrrole/anthracene based materials. J Mater Chem, 2012, 22: $19752-19760$

87 Mun JW, Cho I, Lee D, et al. Acetylene-bridged D-A-D type small molecule comprising pyrene and diketopyrrolopyrrole for high efficiency organic solar cells. Org Electron, 2013, 14: 2341-2347

88 Gao H, Li Y, Wang L, et al. High performance asymmetrical push-pull small molecules end-capped with cyanophenyl for solution-processed solar cells. Chem Commun, 2014, 50: 10251-10254

89 Gao K, Li L, Lai T, et al. Deep absorbing porphyrin small molecule for high-performance organic solar cells with very low energy losses. J Am Chem Soc, 2015, 137: 7282-7285

90 Li Z, Dong Q, Li Y, et al. Design and synthesis of solution processable small molecules towards high photovoltaic performance. J Mater Chem, 2011, 21: 2159-2168

91 Mikroyannidis JA, Stylianakis MM, Balraju P, et al. Novel p-phenylenevinylene compounds containing thiophene or anthracene moieties and cyano-vinylene bonds for photovoltaic applications. ACS Appl Mater Interfaces, 2009, 1: 1711-1718

92 So S, Choi H, Min ko H, et al. Novel unsymmetrical push-pull squaraine chromophores for solution processed small molecule bulk heterojunction solar cells. Solar Energy Mater Solar Cells, 2012, 98 224-232

93 Sharma GD, Mikroyannidis JA, Kurchania R, et al. Organic bulk heterojunction solar cells based on solution processable small molecules $(\mathrm{A}-\pi-\mathrm{A})$ featuring 2-(4-nitrophenyl) acrylonitrile acceptors and phthalimide-based $\pi$-linkers. J Mater Chem, 2012, 22 13986-13995

94 Lin LY, Chen YH, Huang ZY, et al. A low-energy-gap organic dye for high-performance small-molecule organic solar cells. J Am Chem Soc, 2011, 133: 15822-15825

95 Chen YH, Lin LY, Lu CW, et al. Vacuum-deposited small-molecule organic solar cells with high power conversion efficiencies by judicious molecular design and device optimization. J Am Chem Soc, 2012, 134: 13616-13623

96 Chiu SW, Lin LY, Lin HW, et al. A donor-acceptor-acceptor molecule for vacuum-processed organic solar cells with a power conversion efficiency of 6.4\%. Chem Commun, 2012, 48: 1857-1859

97 Wang D, Zhang X, Ding W, et al. Density functional theory design and characterization of $\mathrm{D}-\mathrm{A}-\mathrm{A}$ type electron donors with narrow band gap for small-molecule organic solar cells. Comp Theor Chem, 2014, 1029: 68-78

98 Liu Y, Yang YM, Chen CC, et al. Solution-processed small molecules using different electron linkers for high-performance solar cells. Adv Mater, 2013, 25: 4657-4662

99 Chi LC, Chen HF, Hung WY, et al. Donor-acceptor small molecule with coplanar and rigid $\pi$-bridge for efficient organic solar cells. Solar Energy Mater Solar Cells, 2013, 109: 33-39

100 Paek S, Lee JK, Ko J. Synthesis and photovoltaic characteristics of push-pull organic semiconductors containing an electron-rich dithienosilole bridge for solution-processed small-molecule organic solar cells. Solar Energy Mater Solar Cells, 2014, 120: 209-217

101 Lin HW, Lin LY, Chen YH, et al. A new donor-acceptor molecule with uniaxial anisotropy for efficient vacuum-deposited organic solar cells. Chem Commun, 2011, 47: 7872-7874

102 Sharma GD, Zervaki GE, Angaridis PA, et al. Triazine-bridged porphyrin triad as electron donor for solution-processed bulk heterojunction organic solar cells. J Phys Chem C, 2014, 118: 5968-5977

103 Nazim M, Ameen S, Akhtar MS, et al. Furan-bridged thiazolo $[5,4-d]$ thiazole based $D-\pi-A-\pi-D$ type linear chromophore for solution-processed bulk-heterojunction organic solar cells. RSC Adv, 2015, 5: 6286-6293

104 Liu W, Yao J, Zhan C. Performance enhancement of BODIPY dimerbased small-molecule solar cells using a visible-photon-capturing diketopyrrolopyrrole $\pi$-bridge. RSC Adv, 2015, 5: 74238-74241

105 Sharma GD, Zervaki GE, Angaridis PA, et al. Stepwise co-sensitization as a useful tool for enhancement of power conversion efficiency of dye-sensitized solar cells: the case of an unsymmetrical porphyrin dyad and a metal-free organic dye. Org Electron, 2014, 


\section{5: $1324-1337$}

106 Zervaki GE, Roy MS, Panda MK, et al. Efficient sensitization of dyesensitized solar cells by novel triazine-bridged porphyrin-porphyrin dyads. Inorg Chem, 2013, 52: 9813-9825

107 Liu J, Wang K, Xu F, et al. Synthesis and photovoltaic performances of donor- $\pi$-acceptor dyes utilizing 1,3,5-triazine as $\pi$ spacers. Tetrahedron Lett, 2011, 52: 6492-6496

108 Shu W, Valiyaveettil S. Intramolecular hydrogen bond assisted planarization and self-assembly of simple disc-shaped molecules in mesophases. Chem Commun, 2002, 1350-1351

109 Zou L, Liu Z, Yan X, et al. Star-shaped D- $\pi$-A molecules containing a 2,4,6-tri(thiophen-2-yl)-1,3,5-triazine unit: synthesis and two-photon absorption properties. Eur J Org Chem, 2009, 2009: 5587-5593

110 Leriche P, Piron F, Ripaud E, et al. Star-shaped triazine-thiophene conjugated systems. Tetrahedron Lett, 2009, 50: 5673-5676

111 Omer KM, Ku SY, Chen YC, et al. Electrochemical behavior and electrogenerated chemiluminescence of star-shaped D-A compounds with a 1,3,5-triazine core and substituted fluorene arms. J
Am Chem Soc, 2010, 132: 10944-10952

112 Zhong H, Lai H, Fang Q. New conjugated triazine based molecular materials for application in optoelectronic devices: design, synthesis, and properties. J Phys Chem C, 2011, 115: 2423-2427

Acknowledgments This study was funded by the National Natural Science Foundation of China (21102013) and the Fundamental Research Funds for the Central Universities (DUT16ZD205).

Author contributions Li Y proposed the overall plan of the review article and performed the data analysis. $\mathrm{Wu} \mathrm{R}$ and Yin $\mathrm{L}$ collected the literature and analyzed the data. Wu $\mathrm{R}$ prepared the draft of the manuscript and designed the figures. Yin L and Li Y revised the manuscript. All authors contributed to the general discussion and final revision of the manuscript.

Conflict of interest The authors declare that they have no conflict of interest. 

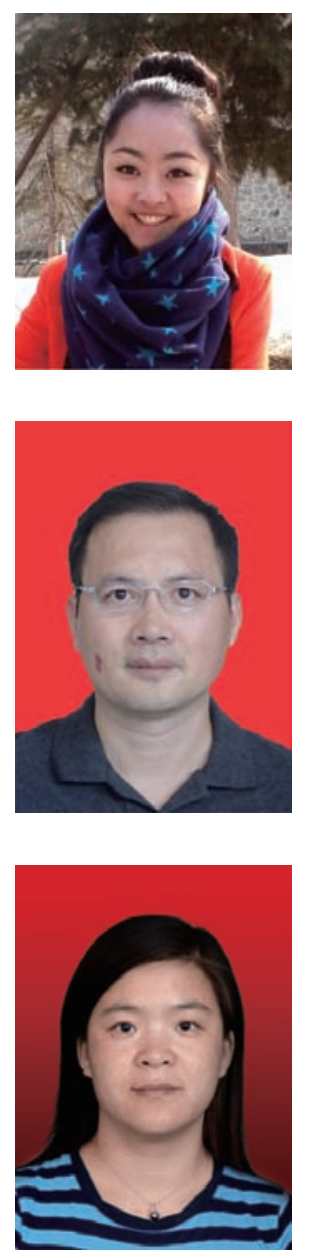

Rui Wu was born in Gansu, China. She earned his BSc degree (2013) in chemistry from Ludong University. She received her MSc degree (2016) in inorganic chemistry from Dalian University of Technology. She joined Prof. Yanqin Li's group as a postgraduate in 2013 and her research focuses on the design and synthesis of organic small molecule photovoltaic materials.
Lunxiang Yin received his PhD degree in 2005 from Humboldt University (Berlin, Germany). He was then a postdoctoral researcher from 2005 to 2007 in the University of California (Davis, USA). He worked as a senior researcher in the National Nanotechnology Laboratory (Lecce, Italy) from 2007 to 2008 . He has been an associate professor in Dalian University of Technology (Dalian, China) since 2008. His research focuses on organic synthesis and optoelectronic materials.

Yanqin Li received her Bachelor and PhD degrees from Jilin University in 1995 and 2000, respectively. From 2000 to 2002, she worked in Hongkong University as a research fellow. From 2002 to 2004, she was a postdoctoral fellow at Humboldt University in Berlin of Germany. From 2004 to 2008, she was a senior researcher in the National Nanotechnology Lab of Italy. She was a visiting scholar at the University of California in Berkeley (UC-Berkeley, USA) from 2006 to 2007. She has been a professor at the Department of Chemistry, Dalian University of Technology since 2008. Her current research interest mainly focuses on organic optoelectronic materials and devices.

\section{推拉结构有机小分子光伏材料中的 $\pi$-桥键效应 \\ 吴睿, 殷伦祥, 李艳芹*}

摘要 在过去的十年中, 推拉结构的有机小分子光伏材料由于分子带隙及光伏性能等易于实现有效的调控, 在光伏领域中受到了广泛的 关注. 适宜的桥键联接对于提升有机太阳能电池的光伏性能起到了重要的作用. 因此 $\pi$-桥键在推拉结构的有机小分子设计中扮演着十分 重要的角色. 本文重点综述了推拉结构有机小分子的不同 $\pi$-桥键（包括噻吩, 烯烃, 炔烃, 芳烃和杂环及其相应的衍生物 ) 对于材料的光 伏性能所产生的重要影响. 这些结果表明, 深入的研究 $\pi$-桥键效应对于深刻理解分子结构和材料性能之间的关系以及通过分子的结构优 化来提高材料的光伏性能具有十分重要的意义. 